\title{
A Meta-analysis of the Uncanny Valley's Independent and Dependent Variables
}

\author{
ALEXANDER DIEL, School of Psychology, Cardiff University, United Kingdom \\ SARAH WEIGELT, Department of Vision, Visual Impairments \& Blindness, Faculty of Rehabilitation \\ Sciences, Technical University of Dortmund, Germany \\ KARL F. MACDORMAN, School of Informatics and Computing, Indiana University, USA
}

\begin{abstract}
The uncanny valley (UV) effect is a negative affective reaction to human-looking artificial entities. It hinders comfortable, trust-based interactions with android robots and virtual characters. Despite extensive research, a consensus has not formed on its theoretical basis or methodologies. We conducted a meta-analysis to assess operationalizations of human likeness (independent variable) and the UV effect (dependent variable). Of 488 studies, 72 met the inclusion criteria. These studies employed 10 different stimulus creation techniques, 39 affect measures, and 14 indirect measures. Based on 247 effect sizes, a three-level meta-analysis model revealed the UV effect had a large effect size, Hedges' $g=1.01[0.80,1.22]$. A mixed-effects meta-regression model with creation technique as the moderator variable revealed face distortion produced the largest effect size, $g=1.46[0.69,2.24]$, followed by distinct entities, $g=1.20[1.02,1.38]$, realism render, $g=0.99[0.62,1.36]$, and morphing, $g=0.94[0.64,1.24]$. Affective indices producing the largest effects were threatening, likable, aesthetics, familiarity, and eeriness, and indirect measures were dislike frequency, categorization reaction time, like frequency, avoidance, and viewing duration. This meta-analysis-the first on the UV effect-provides a methodological foundation and design principles for future research.
\end{abstract}

CCS Concepts: • Human-centered computing $\rightarrow$ HCI design and evaluation methods; $\bullet$ Computer systems organization $\rightarrow$ External interfaces for robotics; $\bullet$ Computing methodologies $\rightarrow$ Animation;

Additional Key Words and Phrases: Anthropomorphism, computer animation, face perception, robotics, uncanny valley

\section{ACM Reference format:}

Alexander Diel, Sarah Weigelt, and Karl F. MacDorman. 2021. A Meta-analysis of the Uncanny Valley's Independent and Dependent Variables. ACM Trans. Hum.-Robot Interact. 11, 1, Article 1 (October 2021), 33 pages. https://doi.org/10.1145/3470742

\footnotetext{
Authors' addresses: A. Diel, School of Psychology, Cardiff University, 70 Park Place, Cardiff CF10 3AT, United Kingdom; email: diela@cardiff.ac.uk; S. Weigelt, Department of Vision, Visual Impairments \& Blindness, Faculty of Rehabilitation Sciences, Technical University of Dortmund, Emil-Figge-Straße 50, 44227 Dortmund, Germany; email: sarah.weigelt@ tu-dortmund.de; K. F. MacDorman, School of Informatics and Computing, Indiana University, 535 West Michigan St., Indianapolis, IN 46202, USA; email: kmacdorm@indiana.edu.

Permission to make digital or hard copies of part or all of this work for personal or classroom use is granted without fee provided that copies are not made or distributed for profit or commercial advantage and that copies bear this notice and the full citation on the first page. Copyrights for third-party components of this work must be honored. For all other uses, contact the Owner/Author.

(c) 2021 Copyright held by the owner/author(s).

2573-9522/2021/10-ART1 \$15.00

https://doi.org/10.1145/3470742
} 


\section{INTRODUCTION}

Royle [2003] gives an evocative and succinct description of the uncanny experience:

The uncanny is ghostly. It is concerned with the strange, weird, and mysterious, with a flickering sense (but not conviction) of something supernatural. The uncanny involves feelings of uncertainty, in particular regarding the reality of who one is and what is being experienced. (p. 1)

Objects, situations, and events that do not fit our everyday understanding of the world are often described as eerie, creepy, or uncanny. These ascriptions can be made regarding new technologies [Langer \& König 2018], unusual human behavior [McAndrew \& Koehnke 2016], or peculiar coincidences [Freud 1919/2003]. Negative evaluations can hinder the adoption of supportive products like healthcare robots [Olaronke Ojerinde \& Ikono 2017] or service chatbots [Ciechanowski et al. 2019]. As the robotics pioneer Mori proposed in 1970, human-looking androids and other objects could elicit a reaction unlike the one typically elicited by people or stylish technology. Mori [2012] illustrated this phenomenon with a graph (Figure 1). The $y$-axis depicts affinity, the dependent variable (DV), as a function of human likeness, the independent variable (IV), on the $x$-axis [Bartneck et al. 2009b; Ho \& MacDorman 2010, 2017; MacDorman \& Ishiguro 2006]. The stimulus sets in Figure 2 show how different creation techniques have been used to operationalize the independent variable.

According to Mori [2012], affinity for an entity increases with its human likeness but only up to a point. Beyond this point, affinity falls and becomes negative, and the entity elicits a cold, eerie, repellant feeling. Then, affinity rises again, becoming positive, as human likeness increases toward indistinguishability. When graphed, the fall and rise in affinity resemble a valley-hence, the term uncanny valley (UV).

Since Mori's proposal, a substantial body of research has replicated a valley-shaped curve and found a significant effect [Burleigh et al. 2013; Ferrey et al. 2015; Jung \& Cho 2018; MacDorman et al. 2009; Mäkäräinen et al. 2014; Mathur \& Reichling 2016; Mathur et al. 2020; McDonnell et al. 2012; Palomäki et al. 2018; Sasaki et al. 2017; Strait et al. 2017; Strait et al. 2015; Tinwell et al. 2015; Tinwell et al. 2011; Tinwell \& Sloan 2014; Yamada et al. 2013]. However, some studies have plotted functions other than a valley-shaped curve: For example, Kätsyri, de Gelder, and Takala [2019] found affinity increased with human likeness, an "uncanny slope"; Cheetham, Suter, and Jäncke [2014] interpreted increasing familiarity ratings with the transition from avatar to ambiguous morph to human as a "happy valley"; and Bartneck, Kanda, Ishiguro, and Hagita [2009a] and Cheetham, Wu, Pauli, and Jäncke [2015] found no difference in affective responses toward androids and humans. Although the UV effect is seldom disputed, its theoretical basis and methodologies have eluded consensus. This motivated us to examine how the independent and dependent variables in Mori's graph have been operationalized in the literature.

Although several reviews have examined the UV effect [Kätsyri et al. 2015; Lay et al. 2016; Wang et al. 2015; Zhang et al. 2020], this is the first meta-analysis to do so. It confirmed the effect's significance and determined its effect size. This is also, of course, the first meta-analysis to evaluate the uncanny valley's stimulus creation methods and affect and indirect measures. The evaluation was accomplished using meta-regression models. From the results, we distill design principles for future experiments.

The UV effect has been conceptualized in different ways. These conceptualizations often stem from different theories and their assumptions about elicitors of the effect [Diel \& MacDorman 2021]. They include: 


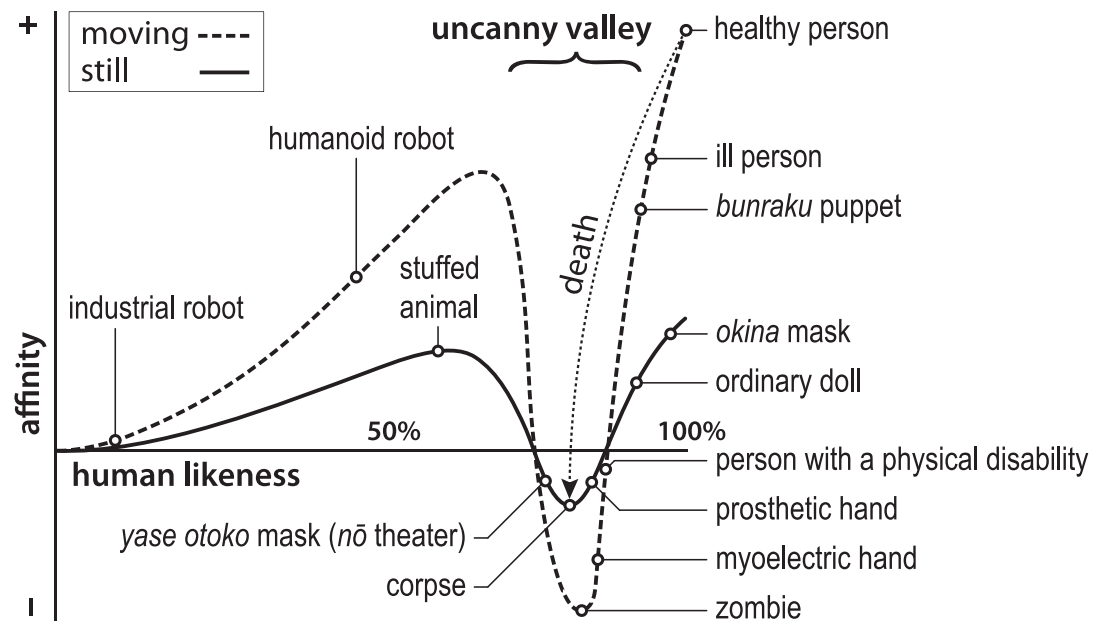

Fig. 1. The uncanny valley as proposed by Mori in 1970. The affective reaction towards an entity ( $y$-axis) is a function of its degree of human likeness ( $x$-axis) and whether it is still or moving (solid or dashed line). Bunraku puppets play character roles in ningyō jōruri, a traditional form of musical puppet theater in Japan. Actors in nō theater wear masks: The yase otoko mask (literally, thin man) signifies a ghost from hell, and the okina mask signifies an old man.

1. a function like Mori's graph that maps a given degree of human likeness to a level of affect [Bartneck et al. 2009a; Burleigh et al. 2013; Chen et al. 2010; Gray \& Wegner 2012; Kätsyri et al. 2019; Lin et al 2021; Ramey 2005; Sasaki et al. 2017; Schneider et al. 2009; Schwind et al. 2018; Seyama \& Nagayama 2007];

2. deviations from norms of human appearance and movement [Chaminade et al. 2007; MacDorman \& Ishiguro 2006; Mathur \& Reichling 2016; Palomäki et al. 2018; Schoenherr \& Burleigh 2015; Seyama \& Nagayama 2007; Tinwell 2009; Tinwell et al. 2014];

3. violations of expectations about human appearance and behavior [Bartneck et al. 2009a; MacDorman \& Ishiguro 2006];

4. sensitivity to nonhuman features that increases with an entity's human likeness [Chattopadhyay \& MacDorman, 2016; Green et al. 2008; MacDorman et al. 2013];

5. a mismatch between human and nonhuman features [Ho \& MacDorman, 2010; MacDorman et al. 2009; Mitchell et al. 2011b; Moore 2012; Takahashi et al. 2015; Tinwell \& Sloan 2014];

6. entities that elicit the concept human but have nonhuman traits [Steckenfinger \& Ghazanfar 2009]; and

7. difficulty distinguishing between categories, such as human and robot, or a conflict between categories [Cheetham et al. 2013; Cheetham et al. 2011, 2014; Cheetham et al. 2015; Matsuda et al. 2012].

\subsection{The Independent Variable}

1.1.1 Construct. In experiments on the UV effect, the independent variable is typically human likeness or a similar term. However, it is unclear precisely how human likeness relates to the UV curve. Human likeness can be characterized along many dimensions, which interact to create an overall impression of humanness [Bartneck et al. 2009b; von Zitzewitz et al. 2013]. Mori [2012] examines both the outward appearance and the behavior of androids, corpses, and industrial and 
Feng et al., 2018
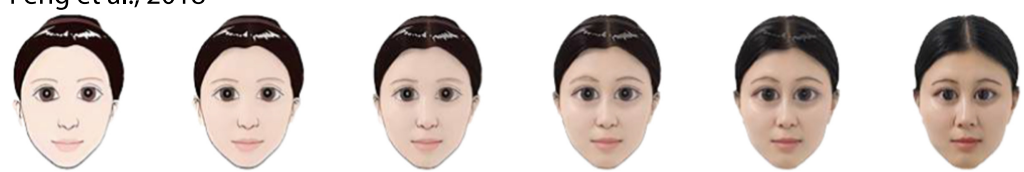

Ferrey, Burleigh, and Fenske, 2015
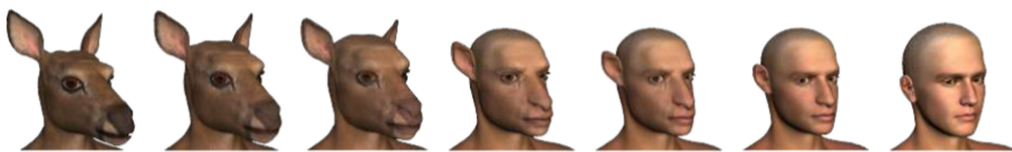

MacDorman et al., 2009
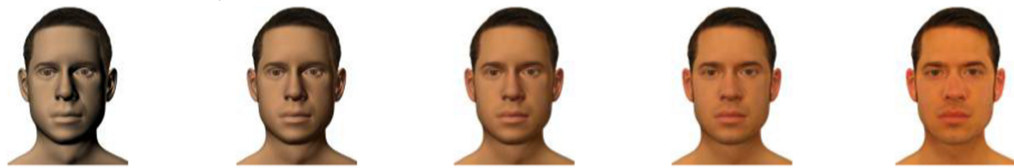

Mäkäräinen, Kätsyri, and Takala, 2014
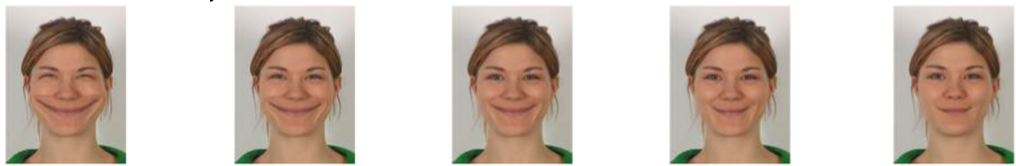

Mathur and Reichling, 2016
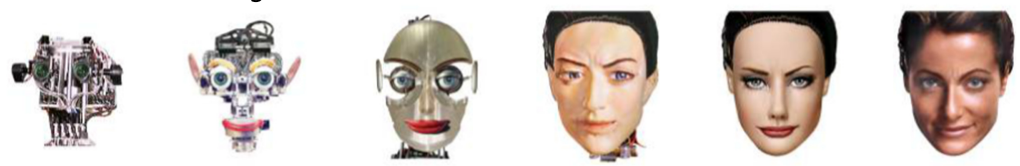

Schindler et al., 2017
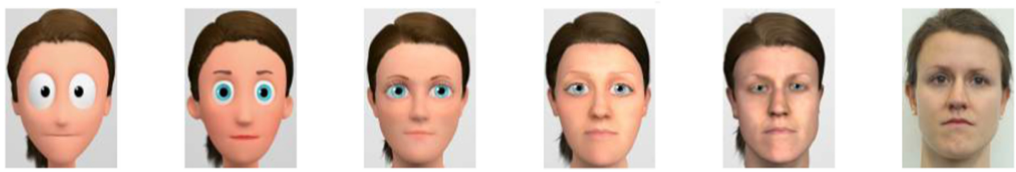

Fig. 2. Different operationalizations of the independent variable human likeness [Feng et al. 2018; Ferrey et al. 2015; MacDorman et al. 2009; Mäkäräinen et al. 2014, derived from Langner et al. 2010; Mathur \& Reichling, 2016; Schindler et al. 2017].

toy robots. In discussing mannequins, prostheses, and bunraku puppets, he draws in other dimensions, such as the setting, lighting, story, time of day, and the perceiver's gender and distance. Research corroborates the multidimensionality of human likeness in exploring the relation between the UV effect and an entity's physical [MacDorman \& Ishiguro 2006; Seyama \& Nagayama 2007], behavioral [MacDorman et al. 2005; Złotowski et al. 2015], and perceived mental similarity to humans [Gray \& Wegner 2012; Stein \& Ohler 2017]. The perception of nonhuman animals can also elicit the UV effect [Chattopadhyay \& MacDorman 2016; Löffler, Dörenbächer \& Hassenzahl 2020; Schwind et al. 2018; Takahashi et al. 2015; Yamada et al. 2013]. This result casts doubt on whether the independent variable solely concerns human likeness. Realism or zoomorphism have served as alternative concepts. Furthermore, Mori [2012] uses human likeness to denote interchangeably both an entity's physical properties and how it is perceived. In research, however, the distinction is necessary. Physical properties, for example, can be directly manipulated as an independent variable. 
1.1.2 Stimulus Range. We compiled a list of categories to summarize stimulus creation techniques. The list derives from the stimuli appearing in publications of empirical research and descriptions of how they were created [e.g., Mitchell et al. 2011b; Seyama \& Nagayama 2007]. We started with six a priori categories and added categories during the literature search when a paper's stimuli did not fit in any existing category. Saturation was reached at 10 categories. The categories encompass the research reviewed, enabling its techniques to be easily classified, and reflect its theoretical and methodological breadth. The 10 categories of techniques are listed below:

Distinct entities: Selecting images or videos of existing robots, androids, computer-animated characters, humans, or other entities [e.g., Mathur et al. 2020]. This technique is theoryindependent and can be used with both still and moving entities, such as characters from films, video games, and virtual worlds.

Emotion manipulation: Distorting affective expressions [e.g., Qiao \& Roger 2011; Qiao et al. 2011; Tinwell et al. 2014]. This technique visually manipulates the emotional expression of the face. It has been used mainly to test empathy-related theories.

Face distortion: Distorting facial features and proportions [e.g., Mäkäräinen et al. 2014]. This technique visually manipulates facial features or the relations among them until the face no longer appears real. The emotional expression is not intentionally manipulated. This technique has been used to test theories related to configural processing [e.g., MacDorman et al. 2009].

Mismatch: Swapping facial features with those of another face that differs along one or more dimensions-typically animacy, human likeness, or realism [e.g., Seyama \& Nagayama 2007]. This technique has been used to test theories related to perceptual mismatch [MacDorman \& Chattopadhyay 2016].

Morphing: Varying the stimulus in a stepwise transition between a pair of images to create a range of stimuli [e.g., MacDorman \& Ishiguro 2006]. This technique has been used to transform the stimulus gradually from one kind of entity to another, thus making it suitable for testing categoryrelated theories [e.g., Cheetham et al. 2015; Sasaki et al. 2017].

Motion manipulation: Distorting an animation's biological motion [e.g., gait, Destephe et al. 2014; Handzic \& Reed 2015; motion quality, Piwek et al. 2014; Thompson et al. 2011]. This technique has been used to test whether the UV effect occurs in motion perception.

Realism render: Varying how real the stimuli appear by representing them as cartoons or as computer models with a reduced polygon count or simplified textures [e.g., McDonnell et al. 2012; Muniady \& Ali 2020]. This technique is theory-independent and relevant to the practical application of visual design.

Real-life encounter: Presenting different embodied entities like robots, androids, and humans for observation or interaction [e.g., Złotowski et al. 2015]. This technique encompasses multiple modalities and, thus, can be used to measure a holistic UV effect. It is also useful because a physical object could be perceived and evaluated differently from its two-dimensional depiction [Snow et al. 2014]. Moreover, this technique is ecologically valid.

Visuo-auditory mismatch: Replacing a human voice with a synthesized voice or vice versa in an animation [e.g., Mitchell et al. 2011b; Stein \& Ohler 2018]. Although typically motivated by perceptual mismatch theories, this technique differs from the mismatch category because the mismatch is crossmodal.

Voice distortion: Distorting natural human voices as auditory stimuli [e.g., Baird et al. 2018; Kühne et al. 2020]. This technique has been used to test whether the UV effect can occur solely within audition.

1.1.3 Measurement. To assess the degree of human likeness (or related concepts), either singlescale measures or indices consisting of multiple scales have been used [e.g., Burleigh et al. 2013; 
Ho \& MacDorman 2010, 2017]. Experiments typically vary the stimulus systematically in its degree of human similarity. Manipulations include distorting it [Mäkäräinen et al. 2014] or controlling its morphing proportion between two images [Cheetham \& Jäncke 2013]. Experiments may include a manipulation check, such as rating the stimulus on human likeness. For computer-modeled stimuli only, Burleigh, Schoenherr, and Lacroix [2013] proposed two objective properties, which they define as follows: texture resolution, the number of pixels per unit of surface area, and polygon count, the number of polygons constituting a three-dimensional model. However, human likeness and realism are two different constructs. Thus, the results of a study measuring human likeness may not be comparable to the results of a study measuring realism. Research has not compared how changes in these independent variables or others may influence affect measures differently.

\subsection{The Dependent Variable}

1.2.1 Construct. Mori [2012] represents the $y$-axis with the term shinwakan, a neologism he translates as affinity. The $y$-axis had initially been translated as familiarity [Reichardt 1978]. Other proposed constructs include interpersonal warmth (or likability) and reverse-scaled eeriness [Bartneck et al. 2009b; Ho \& MacDorman 2010, 2017; Redstone 2013]. Eeriness and its synonym creepiness correlate with aversive experiences like disgust, fear, and anxiety [Ho, MacDorman, \& Pramono, 2008].

1.2.2 Measurement. In experiments on the UV effect, the dependent variable is typically measured with single-scale measures or indices composed of self-reported affective items. Semantic differential scales are common. Semantically, some items like eerie, creepy, and uncanny are specific and, on face value, capture the distinctive experiential quality of the UV effect [Ho \& MacDorman 2010; Mangan 2015; Palomäki et al. 2018; Redstone 2013; Tinwell et al. 2013]. Other items like pleasantness or likability are nonspecific. An entity could rate low on them without being uncanny at all [e.g., items in Bartneck et al. 2009b; Ferrey et al. 2015; Rosenthal-von der Pütten \& Krämer 2014; Yamada et al. 2013].

Questionnaires that have been developed to evaluate robots in general have been repurposed to measure the UV effect. Examples include the Godspeed indices [Bartneck et al. 2009b] and the Robotic Social Attribution Scale [Carpinella et al. 2017]. Ho and MacDorman's [2010, 2017] set of indices includes humanness, interpersonal warmth, attractiveness, and eeriness. They developed the set to decorrelate these dimensions so they could be plotted against each other on orthogonal axes.

Indirect measures may indicate a construct by measuring a different construct. For example, the UV effect may correlate with trust behavior [Mathur \& Reichling 2016]. Implicit measures, grouped here with indirect measures, center on processes that are automatic, effortless, fast, goalindependent, stimulus-driven, uncontrolled, and unintentional. For example, response time and other performance measures of the UV effect typically are implicit measures. Implicit measures counter self-presentational bias, that is, respondents' attempts to influence how others perceive them. Implicit measures may indicate the UV effect in otherwise inaccessible populations, such as infants or nonhuman animals.

Apart from trust behavior, the UV effect has been measured by such indirect measures as avoidance behavior [Matsuda et al. 2012], perceived responsiveness [Tinwell et al. 2013], and cognitive conflict and categorization reaction time [RT, Cheetham \& Jäncke 2013].

1.2.3 Other Constructs. Other constructs and their associated measures and theories include:

Aesthetics: Items measuring aesthetic appeal [Sansoni et al. 2015; Schwind et al. 2018]. These items conceptualize the UV effect as a lack of physical attractiveness. Thus, they can serve as a practical tool for design [Hanson et al. 2005; Ho \& MacDorman 2010, 2017]. Research has used 
nonhuman [e.g., Schwind et al. 2018] as well as human stimuli with the latter leveraging on theories of evolutionary aesthetics. These theories frame the UV effect as resulting from a mechanism for avoiding mates with low fitness as determined by the absence of physical markers of fertility, health, and youthfulness [MacDorman et al. 2009; MacDorman \& Ishiguro 2006].

Animacy and experience: Items measuring perceived animacy [Looser \& Wheatley 2010], responsiveness [Tinwell et al. 2014], and mind [Appel et al. 2016]. These items relate to theories about how the perceived presence or absence of these qualities elicits the UV effect. For example, Gray and Wegner [2012] proposed that a machine having conscious experiences-or a human being lacking them-would be perceived as uncanny; the authors' creation techniques are broad: android robot videos, text about a supercomputer, and a photo of a man.

Anomaly: Items measuring an entity's perceived deviation from the norm. Anomaly items, such as strange or weird, are associated with atypicality theories. These theories predict that the UV effect is elicited by an entity whose features cause it to deviate strongly from its prototype [Kätsyri et al. 2015; Strait et al. 2017]. Anomalies are easily created in images, where features can be moved, reflected, rotated, and scaled [e.g., Diel \& MacDorman 2021].

Disgust: Items measuring disgust, a predictor of the UV effect [Ho, MacDorman, \& Pramono 2008]. These items relate to the theory that the UV effect results from an evolved mechanism for pathogen avoidance [MacDorman \& Entezari 2015].

Distinctive experience: Items measuring the UV effect as the subjective experience of uncanniness or eeriness, which may be correlated with fear, anxiety, and disgust [Bartneck et al. 2009a; Ho, MacDorman, \& Pramono 2008]. This research conceives of the UV effect as an experience distinct from general psychological discomfort or anxiety. Gahrn-Andersen [2020] and Mangan [2015] have related the phenomenological study of the uncanny to the theories of Martin Heidegger and William James.

Familiarity: Items measuring the UV effect as feelings of unfamiliarity, based on Reichardt's [1978] translation of shinwakan as familiarity. Typically, in cognitive psychology, familiarity is contrasted with novelty: $0 \%$ familiarity is $100 \%$ novelty. However, when inspecting the $y$-axis of Mori's [2012] graph, the familiar-novel contrast leads to contradiction. On this interpretation, the bottom of the valley lies in negative familiarity, beyond $100 \%$ novelty, which cannot exist. One finds a different interpretation in Freud's [1919/2003] theory of the uncanny. To Freud, the uncanny is not the perception of something novel or unfamiliar. Rather, it is the recollection of something intimately familiar, perhaps from early childhood, that has long been estranged through repression [MacDorman \& Entezari 2015; MacDorman \& Ishiguro 2006]. Freud asserts that repression transforms every emotional affect-including uncanniness-into anxiety (Angst).

General anxiety: Items measuring a state of anxiety or stress without relating it specifically to the subjective experience of the uncanny. The items are associated with theories based on category inhibition, cognitive conflict [Ferrey et al. 2015], and perceptual tension [Moore 2012]. Their use may reflect the assumption that the experiential quality of the UV effect is no more specific than the psychological discomfort caused by cognitive dissonance or cognitive load.

Interpersonal warmth: Items measuring the primary dimension of social perception, interpersonal warmth, which accounts for $53 \%$ of the variance in perceptions of social behaviors [Fiske et al. 2007; Fiske et al. 2002]. This dimension is measured with positive affect items, like likable, pleasant, and friendly, which load on the same factor in factor analyses [Bartneck et al. 2009a; Ho $\&$ MacDorman 2010]. The construct is intended to measure how feelings about an entity change with its degree of human likeness. The dimension is roughly synonymous with affinity, the $y$-axis of Mori's [2012] graph, though as a construct warmth has been more thoroughly investigated. The use of warmth items to measure the UV effect is grounded in the assumption that warmth and uncanniness are inversely related. However, feelings of coldness-the low end of the scale-differ 
from feelings of uncanniness. For example, we might have warm feelings for the conductor (Tom Hanks) in The Polar Express (2004) while also having uncanny feelings because of the way he is computer animated. Furthermore, the generality of warmth items makes them susceptible to confounds. Stimulus evaluation could be influenced by, for example, background, clothing, color, narrative and framing, verbal and nonverbal behavior, interactivity, personality, relationships, and culture [Brink et al. 2019; Kennedy 2014; Łupkowski et al. 2018; MacDorman 2019; Shin et al. 2019]. Thus, warmth items do not indicate the UV effect but a related construct.

Threat: Items measuring a negative emotional response to dead animals, ranked by the species' similarity to living humans, motivated by theories that conceive of the UV effect as an evolved threat-avoidance mechanism [Moosa \& Ud-Dean 2010; Palomäki et al. 2018; Rosenthal et al. 2014]. The entities could also appear threatening because of their ambiguity [McAndrew \& Koehnke 2016].

Trust: Numerical indicators of trust, such as the amount of money invested while playing a game, with a smaller investment indicating less trust. A decrease in trust could result from the UV effect in perceiving android robots or avatars. Mathur and Reichling [2016] relate trust measures to Hardin's [2002] theory of encapsulated interest: We trust those whose interest encapsulates our own. In their game, they raise the question of whether human players were really taking an intentional stance toward the robot or merely acting as if they were.

\section{METHODS}

The lack of consensus in the UV literature, both theoretical and methodological, should now be evident. It motivates our meta-analysis, the first of its kind. We evaluate the effectiveness of stimulus creation techniques as well as affect and indirect measures. Based on the results, we propose empirically derived design principles for future research.

\subsection{Inclusion Criteria}

The meta-analysis only included a study if it met the criteria below based on the information given:

Empirical study: The study contains the results of at least one data analysis conducted by its authors.

Representative participants: The study uses healthy adults, children, or infants. Excluded were studies restricted to a specific subgroup, such as people with autism spectrum disorder.

Relevant stimuli: The stimuli belong to at least one of the 10 creation techniques.

Adequate stimuli: The stimuli lack obvious confounds like noise created by editing images.

Affect or indirect measures: Affect measures include single-scale items or indices used to selfreport an affective appraisal of the stimulus. Indirect measures include everything else. Studies with either or both were included.

Testing a UV hypothesis for statistical significance: The study has one or more hypotheses designed to test the UV effect. For each hypothesis, a test statistic is applied to the collected data. Studies with both significant and nonsignificant effects were included.

Appropriate variables: Testing for a change in an affect or indirect measure resulting from a change in human likeness or a related variable (e.g., realism, zoomorphism). Thus, all studies were experiments.

Effect size determinable: The study must give enough information to calculate an effect size and its variance.

\subsection{Study Search and Selection}

In March 2021, we searched PubMed, Science.Gov, and the Web of Science for papers with uncanny valley in their title, abstract, or keywords. After removing 33 duplicates, 488 studies 


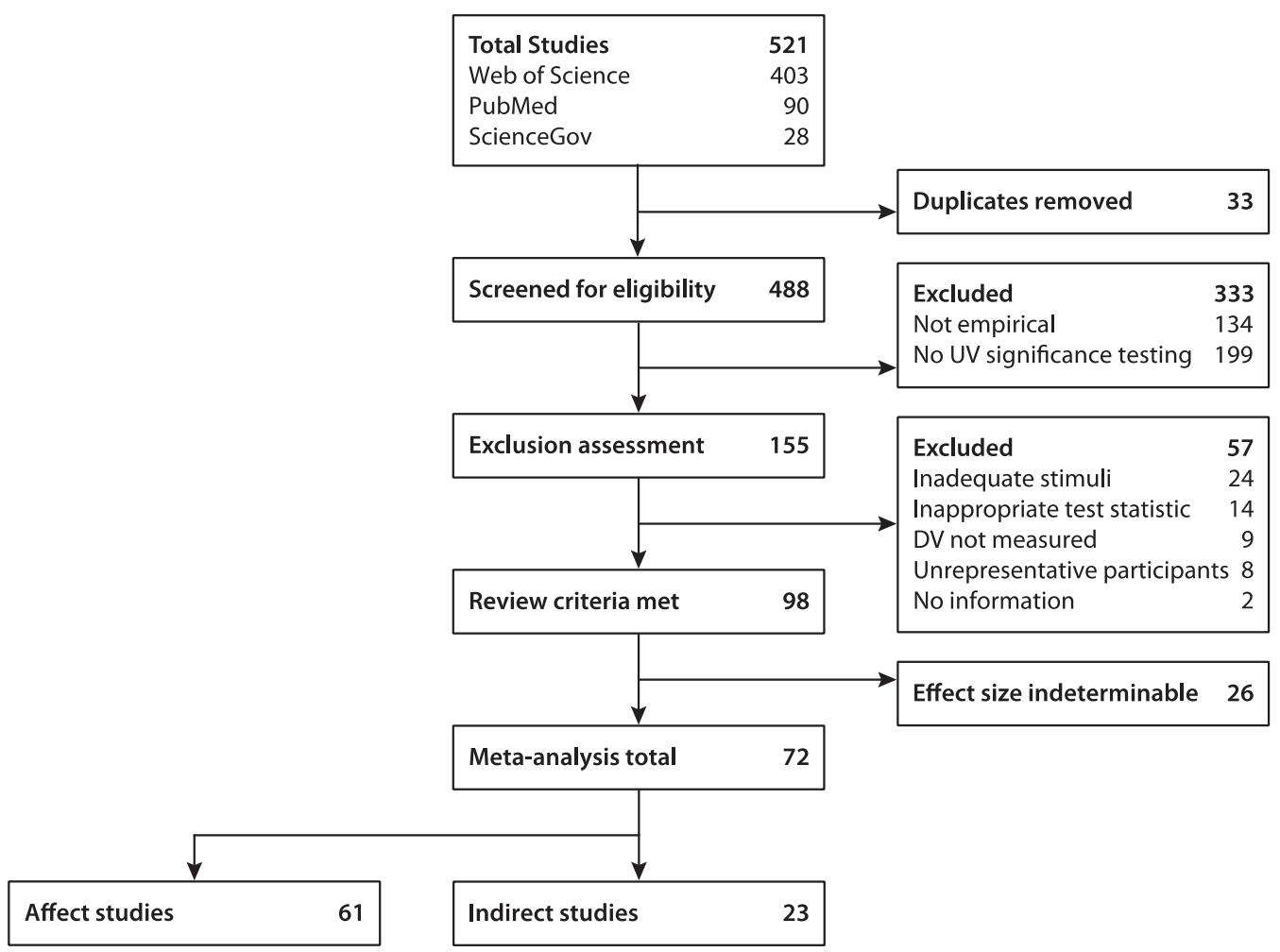

Fig. 3. The flowchart depicts the process of study selection.

remained of which 155 included UV significance testing (see Data Availability). Although 98 met other review criteria, only 72 had determinable effect sizes. These studies appeared in 56 papers published from 2008 to 2021 . Figure 3 summarizes the article selection process.

From its description, we placed each IV operationalization under the best-fitting stimulus creation technique.

For DV operationalizations, single items were generally grouped separately. Nouns formed from adjectives were grouped with those adjectives (e.g., eeriness with eerie). The item creepy and semantic differential scales like creepy-friendly and creepy-pleasant were group as creepy*. Affect measures were grouped separately from indirect measures. For example, the item trustworthy was counted as an affect measure, separate from trust behavior, an indirect measure. If a study used a negative variant of an often-used positive item, the item was grouped with the positive variant (e.g., unpleasant with pleasant). Indices used in multiple studies were counted as separate index items and marked with the suffix $-i$ [e.g., those developed by Bartneck et al., 2009b; Ho and MacDorman, 2010, 2017; Schwind et al. 2018].

We then recorded or calculated effect sizes and effect size variances, labeling each with its corresponding IV and DV. If a study used more than one IV or DV operationalization, each effect size was recorded or calculated.

\subsection{Data Analysis}

A random-effects model was selected for the meta-analysis because study populations and designs differed and affect and indirect measures were used in combination with different stimulus 
creation techniques. A three-level model was used with effect nested by study. The meta-regression for moderation analysis was performed using a mixed-effects model. The model was fitted by restricted maximum-likelihood estimation.

Effect size is reported here as Hedges' $g$. The effect size, its $95 \%$ confidence interval, and the number of measures from which it was derived, $k$, are all reported. Effect size is interpreted with small $=0.20$, medium $=0.50$, and large $=0.80$ thresholds .

If three or more conditions were compared, such as robot, android, and human, two separate g's were calculated: one for the posited descent from the first peak in Mori's graph to the base of the valley and the second for the posited ascent from the base of the valley to the second peak. For convenience, the descent is denoted as the UV's nonhuman side and the ascent as the UV's human side.

The definition of an influential effect was adopted from Viechtbauer and Cheung [2010], as explained in the results section.

Moderator variables for the independent variable were the creation technique. Moderator variables for the dependent variable were (separately) the side of the valley, side $\times$ valence (positive or negative) $\times$ measure type (affect or indirect), affect measure, indirect measure, and other construct. Finally, paper was used as a moderator variable.

2.3.1 Effect Size Calculation. The meta-analysis used the standardized mean difference and its variance. Hedges' $g$ was used to correct for the positive bias of Cohen's $d$ in smaller studies,

$$
\begin{gathered}
g=d\left(1-\frac{3}{4 \mathrm{df}-1}\right), \\
v_{g}=v_{d}\left(1-\frac{3}{4 \mathrm{df}-1}\right)^{2},
\end{gathered}
$$

where $d f$ indicates the degrees of freedom [Borenstein et al. 2011]. If a study did not report $g$, it was calculated from the means and standard deviations or by converting another reported measure of effect size. For within-group studies, which were the majority, $d_{\mathrm{av}}$ and $v_{\mathrm{av}}$ were used,

$$
\begin{gathered}
d_{\mathrm{av}}=\frac{m_{1}-m_{2}}{\frac{1}{2}\left(s_{1}+s_{2}\right)}, \\
v_{d_{\mathrm{av}}}=\frac{1}{n}+\frac{d^{2}}{2 n},
\end{gathered}
$$

where $n$ is the number of participants [Lakens 2013]. This approach leads to slightly wider confidence intervals than $d$ for repeated measures. However, the calculation of $d_{\text {rm }}$ requires the correlation between means, which no study reported. For ANOVAs, $\eta^{2}$ was first calculated:

$$
\eta^{2}=\frac{F \times \mathrm{df}_{1}}{F \times \mathrm{df}_{1}+\mathrm{df}_{2}}
$$

Next, to calculate $g, \eta^{2}$ was converted to $d$ [Cohen 1988]:

$$
d=2 \sqrt{\frac{\eta^{2}}{1-\eta^{2}}}
$$

$R^{2}$, Pearson's $r$, and Cramér's $V$ were plugged into the same formula. For the $t$ statistic, $d$ was calculated for between-groups studies by imputing $r=0.5$ in the formula

$$
d=t \sqrt{\frac{2(1-r)}{n}} .
$$




\section{RESULTS}

The 72 studies in the meta-analysis employed 10 different stimulus creation techniques and 53 different measures, 39 of which were affect measures and 14 of which were indirect measures.

In total, 61 studies included affect measures, and 23 included indirect measures. The studies ranged in size from 10 to 1,311 participants with a median size of 64.5 and an interquartile range of 34 to 203.5. Of the 249 measured effects, 85 involve the nonhuman side of the UV, 71 involve the human side, and 93 involve both sides simultaneously.

The three-level meta-analysis model, including two outliers, revealed that the UV effect had a large effect size, $g=0.95[0.76,1.14], p<.001, k=249$, Akaike information criterion $(A I C)=724.92$, $Q E(248)=10,241.38, p<.001, Q M(1)=93.30, p<.001$. Excluding the two outliers, discussed below, increased the effect size, $g=1.01[0.80,1.22], p<.001, k=247$.

\subsection{Three-level Model}

The meta-analysis often draws multiple effect sizes from the same paper and even from the same study. Thus, the effect sizes are not statistically independent [Cheung 2019]. To address this, we investigated different three-level models.

The model with the lowest estimated prediction error, excluding outliers, has paper as its higherorder grouping variable and effect as its nested lower-order grouping variable, $Q E(246)=9725.21$, $p<.001, Q M(1)=88.53, p<.001$. The model has lower estimated prediction error (paper/effect: AIC $=675.17$ ) than the other three-level models (study/effect: $A I C=683.05$, technique/effect: $A I C$ $=714.85$, measure/effect: $A I C=715.20)$. Its prediction error is significantly lower than two-level models (effect: $A I C=717.57, p<.001$, paper: $A I C=4915.67, p<.001)$. Of the total variance, $38.53 \%$ is between-paper heterogeneity, $60.34 \%$ is within-paper heterogeneity (total $I^{2}=98.87$ ), and $1.13 \%$ is sampling error.

\subsection{Bias}

Figure 4a shows a funnel plot of effect sizes against their standard errors for this meta-analysis. Since standard error is inversely proportional to sample size, larger studies appear at the top and smaller studies at the bottom. In the absence of bias, sampling error should distribute effect sizes randomly but symmetrically about their weighted mean. In the funnel plot, however, the effect sizes tend to increase with their standard errors. A regression test with standard error as the predictor variable and Hedges' $g$ as the outcome variable indicated significant funnel plot asymmetry $(z=6.72, p<.001, k=249)$.

Funnel plot asymmetry could result from publication bias because the meta-analysis relied on published data only. In general, studies reporting a significant effect are more likely to be published. If a true effect exists, a smaller study will require a larger effect size to reach significance. Moreover, given that large studies constitute a major commitment of resources, they are more likely to be published even if their effects are nonsignificant.

One approach to addressing bias is to limit the meta-analysis to larger studies and then to check whether bias is still present and whether the effect size is still large enough to be of substantive importance [Borenstein et al. 2009]. We tried a version of this approach by excluding the effects with the largest standard errors and retesting for funnel plot asymmetry. After excluding 66 effectsthat is, $27 \%$ of the total, as shown in Figure $4 \mathrm{~b}-$ funnel plot asymmetry for the remaining effects became nonsignificant $(z=1.95, p=.051, k=183)$. The effect size, however, was reduced $28 \%$, $g=0.68[0.51,0.85], k=183$. Though smaller, it remains of substantive importance.

Bias was next assessed by $p$-curve analysis. A plot of $p$ values against percentage of effects should be flat if there is no effect and right skewed if there is one. A left skew indicates bias, a 

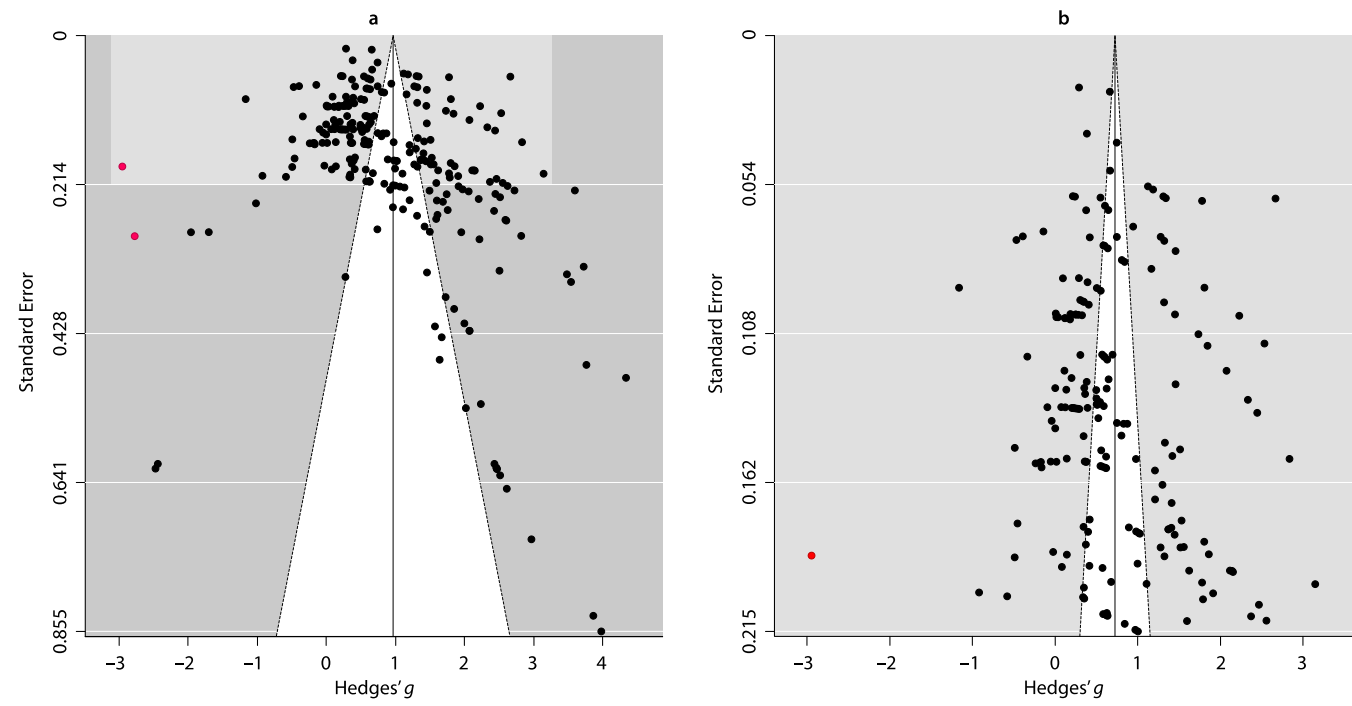

Fig. 4. The funnel plot graphs effect sizes from the meta-analysis against their standard errors: (a) all standard errors; (b) the lowest $73 \%$ of standard errors. Influential effects are indicated in red.

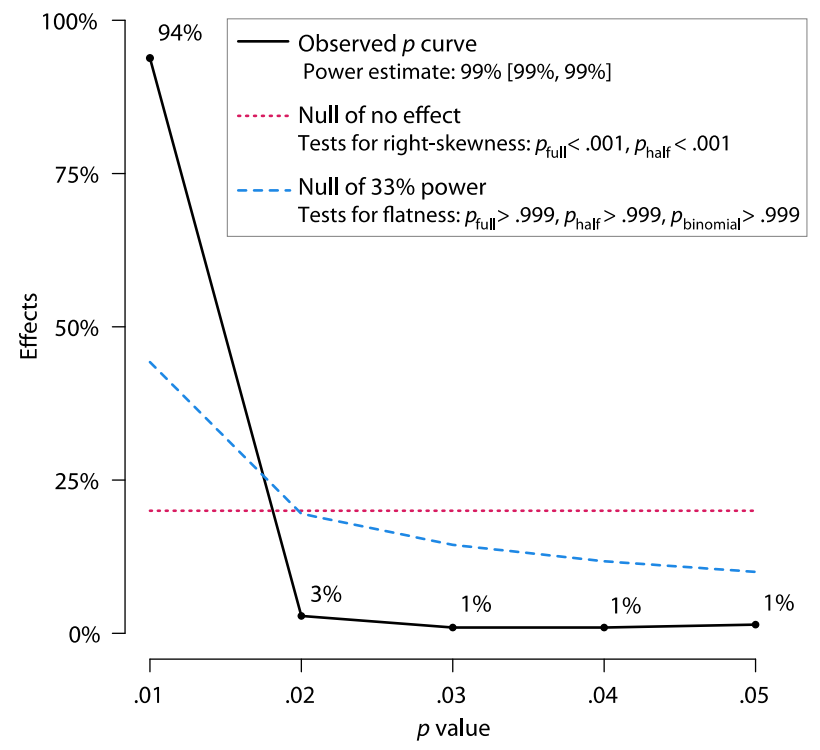

Fig. 5. The $p$-curve for the meta-analysis's 249 effects.

publication environment in which obtaining significance at the .05 level is incentivized, but lower $p$ values are unnecessary. This could result from publication bias or from $p$-hacking, mining the data for patterns and then failing to control for multiplicity in reporting significance. Of 249 effects, $p \leq .05$ for $213(86 \%)$, and $p \leq .025$ for $207(83 \%)$. The right-skewness test, $p_{\text {binomial }}<.001, z_{\text {full }}=$ -73.80 , p pull $<.001, z_{\text {half }}=-72.50$, phalf $<.001$, was significant, which indicates a true effect (Figure 5). The flatness test was nonsignificant, $p_{\text {binomial }}>.999, z_{\text {full }}=65.35, p_{\text {full }}>.999, z_{\text {half }}=69.70$, $p_{\text {half }}$ $>$.999; thus, the test did not indicate insufficient power or the absence of a true effect. The power 

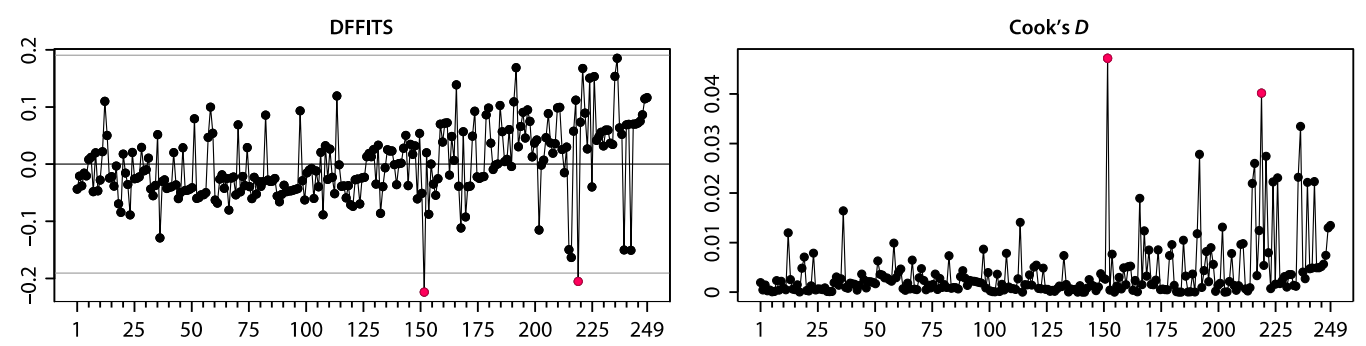

Fig. 6. DFFITS and Cook's $D$ for the effects in the meta-analysis, sorted from lowest to highest standard error. Influential effects are indicated in red.

estimate is $0.99[0.99,1.00]$. The tests were repeated, with similar results, for only the 66 effects with the largest standard errors. Thus, $p$-curve analysis supports the conclusion that the effect is true. It is not simply the result of publication bias or $p$-hacking.

\subsection{Influential Effects}

Viechtbauer and Cheung [2010] proposed that an effect is influential if it meets one of the following four criteria:

$$
\mid \text { DFFITS } \mid>3 \sqrt{\frac{p}{k-p}},
$$

where $p$ is the number of model coefficients and $k$ the number of effects, the Cook's distance,

$$
D_{i}>\chi_{p, 50 \%}^{2},
$$

where $p$ is the model's degrees of freedom, indicating the deletion if the $i$ 'th effect decreases the Mahalanobis distance between effects,

$$
\text { hat }>\frac{3 p}{k}, \text { and any }
$$

$$
\text { DFBETA }>1 .
$$

Two effects were identified as influential by the first two criteria (Figure 6), and both pertained to the UV's nonhuman side: Rosenthal et al.'s [2014] unfamiliar-i, $g=-2.95$, DFFITS $=-0.224$, $D=0.047$, hat $=0.004$, DFBETA $=-0.224$, and Wang et al.'s [2020] alive, $g=-2.77$, DFFITS $=$ $-0.205, D=0.040$, hat $=0.004$, DFBETA $=-0.205$. They were treated as outliers for reasons discussed below and included in analyses selectively.

\subsection{Independent Variable Operationalizations}

3.4.1 Moderator: Creation Techniques. Moderation analysis was performed, excluding outliers, using a mixed-effects meta-regression model with effect as the random variable and creation technique as the moderator variable, $A I C=701.33, Q E(237)=8984.08, p<.001, \tau^{2}=0.91, I^{2}=98.62$, $Q M(10)=272.53, p<.001$. Face distortion produced the largest effect size, followed by distinct entities, realism render, and morphing (Figure 7).

Distinct entities studies typically used stimuli that could have confounding effects (e.g., body language, facial expressions, lighting, viewing perspective). To reduce their risk, a few studies applied standards for stimulus selection-for example, full face shown in frontal or three-fourths aspect, resolution sufficient to generate a final image three inches in height at $100 \mathrm{dpi}$, and no other body parts visible [Brink et al. 2017; Mathur \& Reichling 2016]. When only distinct entities studies with standardized stimuli were considered, three in total, $g$ fell to $0.82[-0.12,1.77], k=4$, and the effect became nonsignificant, $p=.089$. 


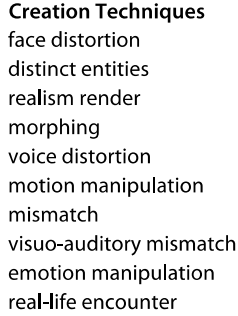

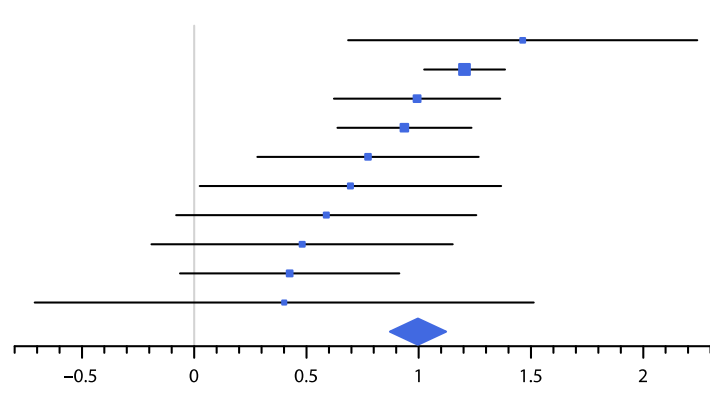

$\begin{array}{rr}\boldsymbol{g} & \mathbf{C l} \\ 1.46 & {[0.69,2.24]} \\ 1.20 & {[1.02,1.38]} \\ 0.99 & {[0.62,1.36]} \\ 0.94 & {[0.64,1.24]} \\ 0.77 & {[0.28,1.27]} \\ 0.70 & {[0.02,1.37]} \\ 0.59 & {[-0.08,1.26]} \\ 0.48 & {[-0.19,1.15]} \\ 0.42 & {[-0.06,0.91]} \\ 0.40 & {[-0.71,1.51]} \\ 1.00 & {[0.87,1.12]}\end{array}$

$k$
6
112
27
44
16
8
8
8
15
3
247

Fig. 7. Creation technique is the moderator variable in the meta-regression model. For each of its values, Hedges' $g$, the $95 \%$ confidence interval, and number of effects $(k)$ are listed. The position of the blue square depicts the effect size, and its relative size depicts the precision. The width of the diamond depicts the confidence interval of the summary effect size.

Four studies used nonhuman animal stimuli, $A I C=32.95, Q E(17)=373.46, p<.001$, $Q M(1)=32.95, p<.001$ [MacDorman \& Chattopadhyay 2017; Schwind et al. 2018; Yamada et al. 2013]. Their 18 effects were all significant, $g=1.94[1.28,2.60], k=18$. Stimulus operationalization techniques for animal stimuli were comparable with those for human stimuli, including distinct entities [Rativa et al. 2020; Takahashi et al. 2015], emotion manipulation, face distortion, realism render [Chattopadhyay \& MacDorman 2016; Schwind et al. 2018], and morphing [Yamada et al. 2013].

\subsection{Dependent Variable Operationalizations}

3.5.1 Moderator: Side of the Uncanny Valley, Valence, and Type of Measure. Moderation analysis was performed, including outliers, with effect as the random variable and side of the valley as the moderator variable, $A I C=731.92, Q E(246)=9942.04, p<.001, \tau^{2}=1.00, I^{2}=98.80, Q M(3)=239.92$, $p<.001$. If possible, an effect size was calculated for each side of the uncanny valley. However, this was not possible for $37 \%$ of effect sizes, usually because the means and standard deviations were not reported. In these cases, a combined effect size for both sides of the valley was calculated (e.g., based on an $F$ statistic). For the human side, $g=1.34$ [1.10, 1.57], $p<.001$, and $k=71$, for the nonhuman side, $g=0.64[0.43,0.86], p<.001$, and $k=85$, and for both sides, $g=0.98[0.77$, $1.19], p<.001$, and $k=93$. Thus, the effect size for the human side was more than double that of the nonhuman side.

To investigate this disparity, we repeated the analysis with side $\times$ valence (positive or negative) $\times$ measure type (affect or indirect) as the moderator variable (Figure 8 ). The combined value human positive affect had the largest affect size, $g=1.69$ [1.34,2.03], $p<.001, k=32$ and nonhuman positive affect had the smallest. Thus, among all measures, positive affect measures were the most effective at measuring the human side of the valley and the least effective at measuring the nonhuman side. A Wald-type test revealed this difference in effectiveness was significant, $Q M(12)=276.73$, $p<.001$. For the human side, affect measures were more effective than indirect measures. For the nonhuman side, indirect measures were more effective than affect measures, and negative measures were more effective than positive ones.

3.5.2 Moderator: Affect Measures. Moderation analysis was performed, excluding outliers, with effect as the random variable and affect measure as the moderator variable, AIC $=537.05, Q E(159)$ $=4544.64, p<.001, \tau^{2}=0.92, I^{2}=98.51, Q M(38)=247.70, p<.001$ (Figure 9). Indices producing effects that were larger than average include threatening-i (threatening, eerie, uncanny, dominant, harmless), likable-i (pleasant, likable, attractive, familiar, natural, intelligent), aesthetics- $i$ 


\section{Sides of the Valley}

human: +ve affect

nonhuman:-ve indirect

both: -ve indirect

human: -ve affect

human:-ve indirect

both: +ve affect

nonhuman: +ve indirect

both: +ve indirect

both:-ve affect

nonhuman: -ve affect

human: +ve indirect

nonhuman: +ve affect

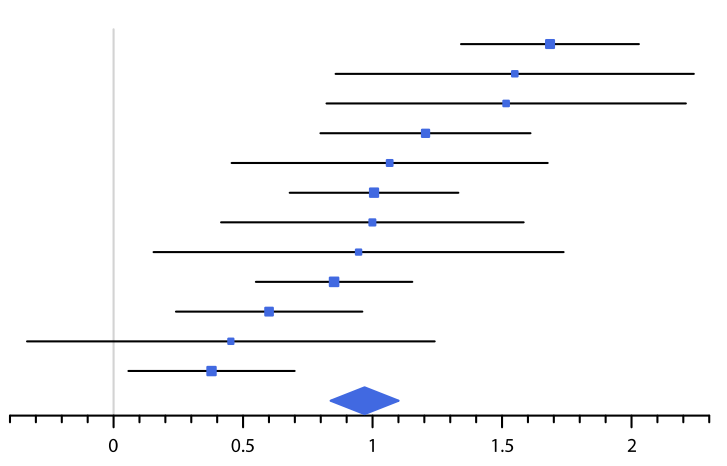

$\boldsymbol{g}$
1.69
1.55
1.52
1.20
1.07
1.01
1.00
0.95
0.85
0.60
0.45
0.38
$\mathbf{0 . 9 7}$

$[1.34,2.03]$

$[0.86,2.24]$

$[0.82,2.21]$

$[0.80,1.61]$

$[0.46,1.68]$

$[0.68,1.33]$

$[0.41,1.58]$

$[0.15,1.74]$

$[0.55,1.15]$

$[0.24,0.96]$

$[-0.33,1.24]$

$[0.06,0.70]$

$[0.84,1.10]$

Fig. 8. Side of the uncanny valley is the moderator variable in the meta-regression model.

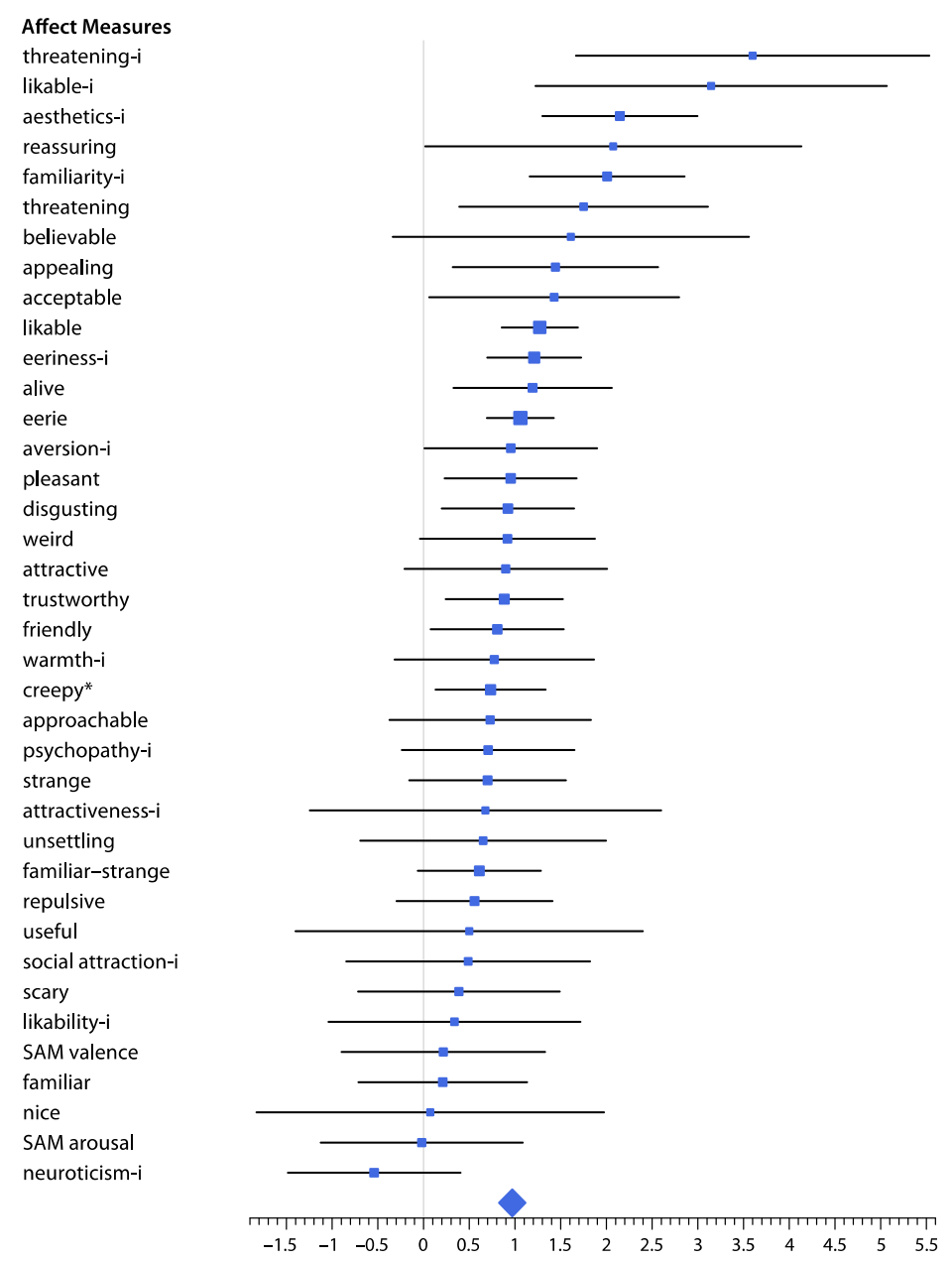

$\begin{array}{rrr}\boldsymbol{g} & \mathrm{Cl} & \boldsymbol{k} \\ 3.60 & {[1.67,5.53]} & 1 \\ 3.15 & {[1.22,5.07]} & 1 \\ 2.15 & {[1.30,2.99]} & 5 \\ 2.07 & {[0.02,4.13]} & 1 \\ 2.01 & {[1.16,2.85]} & 5 \\ 1.75 & {[0.39,3.11]} & 2 \\ 1.61 & {[-0.34,3.56]} & 1 \\ 1.44 & {[0.32,2.57]} & 3 \\ 1.43 & {[0.06,2.80]} & 2 \\ 1.27 & {[0.85,1.69]} & 23 \\ 1.21 & {[0.70,1.72]} & 14 \\ 1.19 & {[0.33,2.06]} & 5 \\ 1.06 & {[0.69,1.42]} & 28 \\ 0.95 & {[0.01,1.90]} & 4 \\ 0.95 & {[0.23,1.67]} & 7 \\ 0.92 & {[0.20,1.65]} & 7 \\ 0.92 & {[-0.04,1.87]} & 4 \\ 0.90 & {[-0.21,2.01]} & 3 \\ 0.88 & {[0.24,1.52]} & 9 \\ 0.81 & {[0.08,1.53]} & 7 \\ 0.77 & {[-0.32,1.87]} & 3 \\ 0.73 & {[0.13,1.33]} & 10 \\ 0.73 & {[-0.37,1.83]} & 3 \\ 0.71 & {[-0.24,1.65]} & 4 \\ 0.70 & {[-0.16,1.56]} & 5 \\ 0.68 & {[-1.25,2.60]} & 1 \\ 0.65 & {[-0.69,2.00]} & 2 \\ 0.61 & {[-0.06,1.28]} & 8 \\ 0.56 & {[-0.30,1.41]} & 5 \\ 0.50 & {[-1.40,2.40]} & 1 \\ 0.49 & {[-0.85,1.82]} & 2 \\ 0.39 & {[-0.72,1.49]} & 3 \\ 0.34 & {[-1.04,1.72]} & 2 \\ 0.22 & {[-0.90,1.33]} & 3 \\ 0.21 & {[-0.71,1.13]} & 5 \\ 0.07 & {[-1.83,1.97]} & 1 \\ -0.02 & {[-1.13,1.09]} & 3 \\ -0.54 & {[-1.49,0.40]} & 4 \\ 0.97 & {[0.83,1.11]} & 197 \\ & & \end{array}$

Fig. 9. Affect measure is the moderator variable in the meta-regression model. Creepy ${ }^{*}$ combines the item creepy with scales including the term, such as creepy-pleasant and creepy-friendly. 

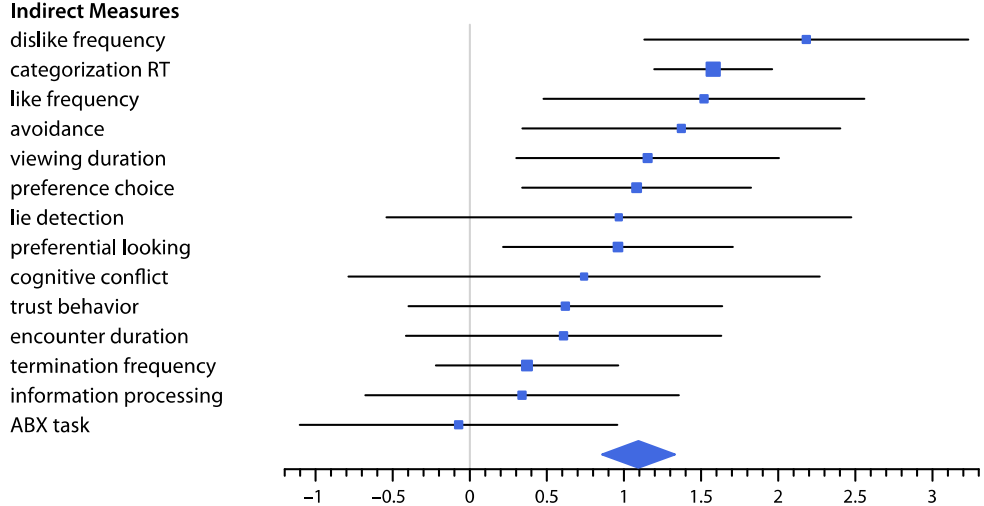

Cl $k$

$[1.13,3.23] \quad 2$

Fig. 10. Indirect measure is the moderator variable in the meta-regression model.

(ugly-beautiful, unaesthetic-aesthetic), familiarity-i (uncanny-familiar, freaky-numbing), and eeriness-i (dull-freaky, predictable-eerie, plain-weird, ordinary-supernatural, boring-shocking, uninspiring-spine-tingling, predictable-thrilling, bland-uncanny, unemotional-hair-raising). Individual items include reassuring, threatening, believable, appealing, acceptable, alive, and eerie. However, when the two outliers are included, alive falls from the 12th highest effect size, $g=1.19[0.33$, 2.06], $p=.007, k=5$, to the 29th, $g=0.55[-0.27,1.37], p=.191, k=6$, and is no longer significant. The other outlier, unfamiliar-i (strange, unfamiliar) appears last, $g=-2.95[-4.94,-0.95], p=.004$, $k=1$.

3.5.3 Indices and Multiple Scale Analyses. A variety of terms have been used to measure different constructs underlying the UV effect. The relations among the terms can give insight into the UV effect's experiential quality. In studies with several terms, we investigated their intercorrelations to determine whether they reflect the UV effect or instead a related construct. Table A1 in the Appendix lists the interscale correlations observed in the reviewed research.

As a measure of reliability, 15 studies in the meta-analysis reported the Cronbach's $\alpha$ of the indices used. Ho and MacDorman's [2010,2017] eeriness and warmth indices and their derivations were generally reliable. Distinctive experience terms (e.g., creepy, eerie, and uncanny) tended to load on the same factor [e.g., Destephe et al. 2015; Lischetzke et al. 2017]. In a principal component analysis (PCA), the items uncanny and eerie loaded on the same component as threat-related items, and the items strange and unfamiliar as anxiety-related items [Rosenthal-von der Pütten \& Krämer 2014; Ho, MacDorman, \& Pramono 2008, found fear and disgust to be stronger predictors of eerie and creepy than anxiety]. In a similar vein, removing strange from an index consisting of eerie, unsettling, and strange improved its reliability [Kätsyri et al. 2017]. This indicates uncanniness and strangeness may be different constructs.

Finally, likable, friendly, pleasant, and other warmth items typically comprise reliable indices [e.g., Kätsyri et al. 2017; Rosenthal-von der Pütten \& Krämer 2014; Tung 2016], which indicates an interpersonal warmth construct for the tested stimuli [e.g., Bartneck et al. 2009a].

3.5.4 Moderator: Indirect Measures. Moderation analysis was performed, excluding outliers, with effect as the random variable and indirect measure as the moderator variable (Figure 10). Dislike frequency, which indicates the number of times disliked, had the largest effect size [Strait et al. 2019], followed by categorization reaction time [Carr et al. 2017; Cheetham \& Jäncke 2013; MacDorman \& Chattopadhyay 2017; Wang \& Rochat 2017; Yamada et al. 2013], like frequency [Strait 


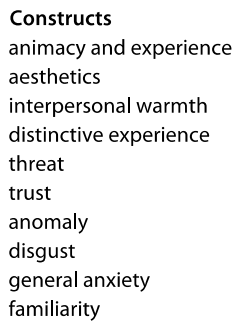

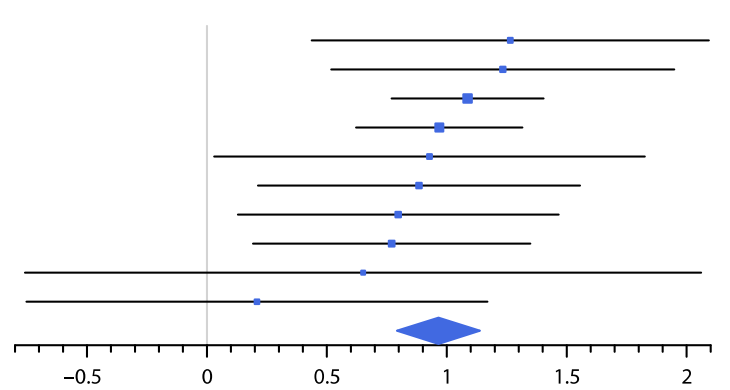

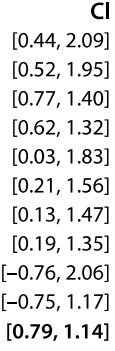

CI

$k$

6

Fig. 11. Construct is the moderator variable in the meta-regression model.

et al. 2019], avoidance behavior attributions to uncanniness [Perez et al. 2020], viewing duration [Strait et al. 2015, 2019], preference choice in a two-alternative forced-choice categorization task [Feng et al. 2018; Prakash \& Rogers 2015], and preferential looking, that is, preferring to view one stimulus more than another [Matsuda et al. 2015; Nitta \& Hashiya 2021].

Nonsignificant effect sizes include lie detection, that is, frequency of rating a statement as a lie [McDonnell \& Breidt 2010], cognitive conflict, operationalized as number of reversals of direction when moving a stimulus with a mouse pointer towards one of two categories [Weis \& Wiese 2017], trust behavior, specifically the amount of money entrusted with an entity in an investment game [Mathur \& Reichling 2016], encounter duration, that is, viewing duration until the participant terminates the encounter [Perez et al. 2020], termination frequency, measured by the number of times terminated [Perez et al. 2020; Strait et al. 2015, 2017, 2019], information processing about an entity, as indicated by the number of personality judgments made [Shin et al. 2019], and ABX task, which entails visual same-different discriminations [Cheetham et al. 2014].

\subsection{Other Constructs}

After grouping measures by other UV construct, moderation analysis was performed, excluding outliers, with effect as the random variable and other construct as the moderator variable, AIC = 386.28, $Q E(122)=2999.63, p<.001, \tau^{2}=1.02, I^{2}=98.29, Q M(10)=119.67, p<.001$ (Figure 11). Animacy and experience had the largest effect size, $g=1.26[0.44,2.09], p=.003, k=6$. However, if outliers are included, this construct falls from first to eighth and becomes nonsignificant, $g=$ $0.70[-0.10,1.51], p=.088, k=7$. Other constructs with significant effects, in decreasing order of effect size, were aesthetics, interpersonal warmth, distinctive experience, threat, trust, anomaly, and disgust. General anxiety and familiarity had nonsignificant effects.

\subsection{Papers}

For reference, a moderation analysis was performed, excluding outliers, with effect as the random variable and paper as the moderator variable, $A I C=585.95, Q E(191)=5058.35, p<.001, \tau^{2}=0.61$, $I^{2}=98.05, Q M(56)=552.95, p<.001$ (Figure 12).

\subsection{Data Availability}

The meta-analysis was performed in the $R$ statistical computing environment with the metafor package. The $p$-curve analysis and variance distribution analysis of the three-level model were performed with the dmetar package. The remaining $R$ packages were devtools, forestplot, ggplot2, and readxl. The dataset, R script, and other supplementary materials are available at https://doi. org/10.17605/osf.io/57sme. 
Papers

Poliakoff et al. (2013)

Wang et al. (2020)

Rosenthal et al. (2014)

Ho \& MacDorman (2017)

Yamada et al. (2013)

Schwind et al. (2018)

Cheetham et al. (2013)

Strait et al. (2017)

McDonnell et al. (2012)

Lischetzke et al. (2017)

Wang \& Rochat (2017)

Matsuda et al. (2015)

Strait \& Scheutz (2014)

Piwek et al. (2014)

Strait et al. (2015)

Reuten et al. (2018)

Destephe et al. (2015)

Sasaki et al. (2017)

Strait et al. (2019)

Kühne et al. (2020)

Perez et al. (2020)

Löffler et al. (2020)

Ferrey et al. (2015)

Cheetham \& Jäncke (2013)

Feng et al. (2017)

MacDorman \& Chattopadhyay (2016)

McDonnell \& Breidt (2010)

Mathur \& Reichling (2016)

Carr et al. (2017)

Tinwell et al. (2011a)

Mitchell et al. (2011)

Mäkäräinen et al. (2014)

Brink et al. (2017)

Weis \& Wiese (2017)

Prakash \& Rogers (2015)

Schwind et al. (2017)

Palomäki et al. (2018)

MacDorman et al. (2009)

Tung (2016)

Zlotowski et al. (2015)

Tinwell \& Sloan (2014)

Shin et al. (2019)

Stein \& Ohler (2018)

Tinwell et al. (2013)

Tinwell et al. (2015)

Nitta \& Hashiya (2021)

Qiao \& Eglin (2011)

Bartneck et al. (2009)

Broadbent et al. (2013)

Kätsyri et al. (2019)

Cheetham et al. (2015)

Kimura \& Yotsumoto (2018)

Destephe et al. (2014)

Cheetham et al. (2014)

Muniady \& Ali (2020)

Baird et al. (2018)

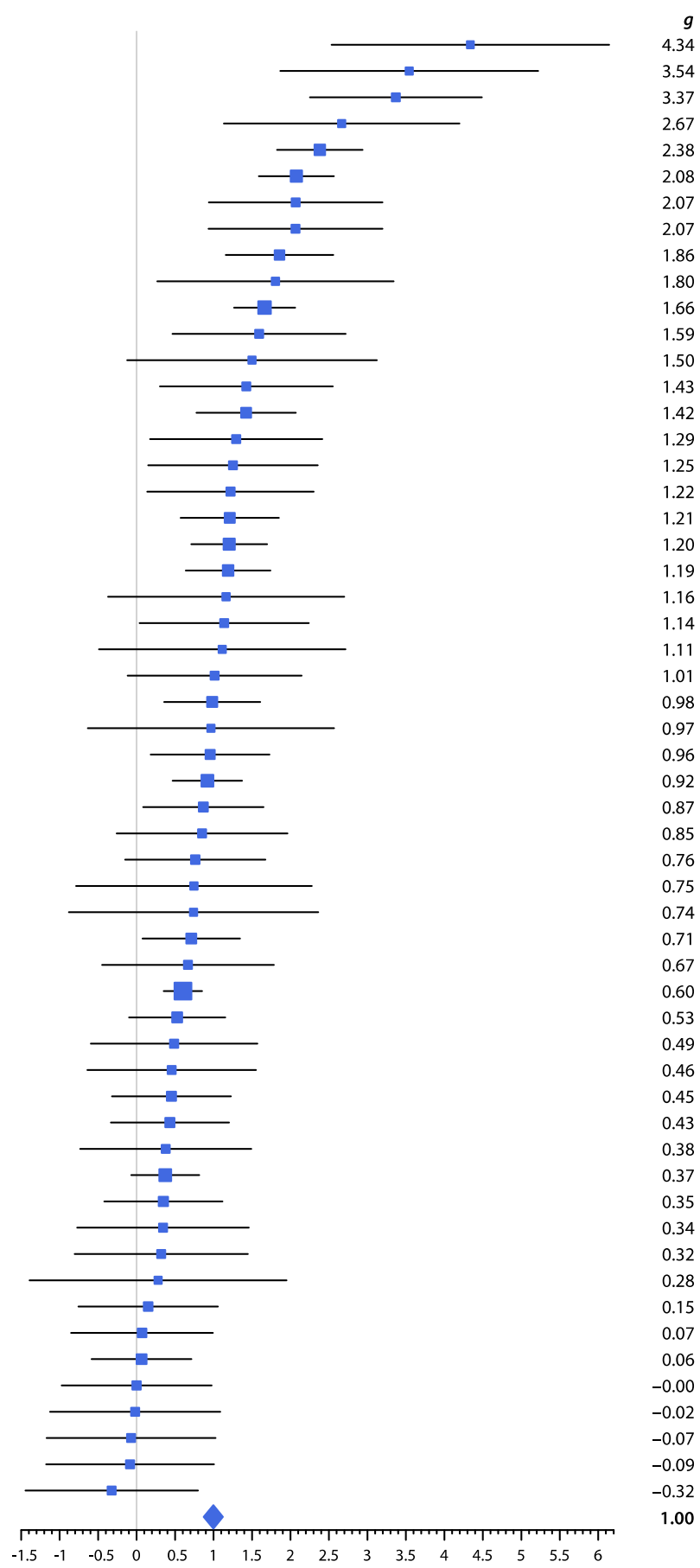

C

$[1.87,5.22]$

$[2.25,4.49]$

$[1.13,4.20]$

$[1.82,2.94]$

$[1.59,2.56]$

$[0.94,3.20]$

$[0.93,3.20]$

$[1.16,2.56]$

$[0.27,3.34]$

$[1.27,2.06]$

$[0.47,2.72]$

$[-0.12,3.12]$

$[0.30,2.55]$

$[0.78,2.07]$

$[0.17,2.41]$

$[0.15,2.35]$

$[0.14,2.30]$

$[0.57,1.85]$

$[0.71,1.70]$

$[0.64,1.74]$

$[-0.37,2.70]$

$[0.04,2.24]$

$[-0.49,2.72]$

$[-0.12,2.15]$

$[0.36,1.61]$

$[-0.63,2.57]$

$[0.18,1.73]$

$[0.47,1.37]$

$[0.08,1.65]$

$[-0.26,1.96]$

$[-0.15,1.67]$

$[-0.79,2.28]$

$[-0.88,2.36]$

$[0.08,1.34]$

$[-0.45,1.78]$

$[0.35,0.85]$

$[-0.10,1.15]$

$[-0.59,1.57]$

$[-0.64,1.55]$

$[-0.32,1.23]$

$[-0.34,1.20]$

$[-0.73,1.49]$

$[-0.07,0.82]$

$[-0.42,1.12]$

$[-0.77,1.46]$

$[-0.81,1.45]$

$[-1.39,1.95]$

$[-0.76,1.06]$

[-0.85, 0.99]

$[-0.58,0.71]$

$[-0.97,0.97]$

$[-1.13,1.09]$

$[-1.17,1.03]$

$[-1.18,1.01]$

$[-1.45,0.80]$

$[0.87,1.12]$

k

2

1

12

10

2

2

6

1
16

2

1

2

6

2

2

10

8

1

2

1

2

6

4

Fig. 12. Paper is the moderator variable in the meta-regression model. 


\section{DISCUSSION}

\subsection{Independent Variable Operationalizations}

Among all the stimulus creation techniques, face distortion produced the largest effect size, followed by distinct entities, realism render, morphing, voice distortion, and motion manipulation. Techniques producing a nonsignificant effect include mismatch, visuo-auditory mismatch, emotion manipulation, and real-life encounter, though real-life encounter was based on only one paper. Nonhuman animal stimuli performed well. Our evaluation of stimulus creation techniques is summarized in Table A2 of the Appendix.

Face distortion was only tested in four of the papers reviewed [Feng et al. 2018; MacDorman et al. 2009; Mäkäräinen et al. 2014; Schwind et al. 2018]. Nevertheless, it is a promising technique to explore configural processing theories [Diel \& MacDorman 2021].

Distinct entities were used in $46 \%$ of significance tests (114 out of 249), more than any other technique. This creation technique has greater ecological validity than all techniques exceptat least for robots-real-life encounter. However, stimuli in these studies typically varied in body language, facial expression, familiarity, gaze direction, lighting, perspective, and other aspects. These potential confounding variables indicate a lack of experimental control, which could limit the generalizability of the results [Kätsyri et al. 2015; Kätsyri et al. 2019]. This interpretation aligns with our results. When the moderation analysis was limited to studies using standardized stimuli, distinct entities produced a nonsignificant effect.

Although morphing produced a large effect size in the meta-analysis, it was nonsignificant for 8 out of 44 effects. Nonsignificance may stem from the choice of endpoint stimuli. Studies that did not find a UV effect used endpoint stimuli with the same shape, such as a human face and a matching avatar face [Cheetham et al. 2015; Kätsyri et al. 2019; the same issue arises for realism render, MacDorman \& Chattopadhyay 2016]. By contrast, studies that did find a UV effect used morphologically different endpoint stimuli to produce a robot-to-human, animal-to-human, or cartoon-to-real transition [Ferrey et al. 2015; Lischetzke et al. 2017; Palomäki et al. 2018; Sasaki et al. 2017].

Creating stimuli from insufficiently distinct endpoint images may result in a morphing sequence with too narrow a range in human likeness to include the uncanny valley part of the graph. For example, although animals and robots have facial proportions that are atypical for humans, they are not judged by human standards. Morphing them with human faces may elicit human-specific processing, heightening sensitivity to those features that still deviate from human proportions, thus eliciting the UV effect. This effect could not occur if the facial proportions of the low human likeness endpoint stimuli were already human (e.g., human avatars). Thus, it is possible that, for morphing stimuli to elicit a UV effect reliably, they must distort an entity's configural pattern, which would support theories predicting the UV effect results from configural processing [Chattopadhyay \& MacDorman 2016; Diel \& MacDorman 2021; Kätsyri 2018].

Alternatively, the large effect sizes for endpoint stimuli that differ greatly in their morphology may be an unintended consequence of the creation technique. Endpoint stimuli like robots and dolls tend to be attractive because they are the product of design. Human beings, though not designed, tend to find each other attractive because their faces and bodies co-evolved with their perceptual and hormonal systems. In this context, attractiveness serves a purpose: It supports mate bonds and parental bonds [see Kozak et al. 2013; Wyman et al. 2011]. However, intermediate stimuli in a morphing sequence neither evolved nor were designed to be perceived as anything. This arbitrariness could heighten their uncanniness.

We advise researchers to avoid using similar endpoint images when creating stimuli through morphing, or to use such techniques as morphing different regions of the face in different 
morphing steps [Seyama \& Nagayama 2007]. However, it is also important to avoid creating strange or ghostly artifacts that could appear eerie for reasons other than their being intermediate in human likeness [discussed in MacDorman \& Chattopadhyay 2016]. The effect of endpoint stimulus choice on the UV effect is a topic for investigation.

In their review, Wang, Lilienfeld, and Rochat [2015] found evidence against the UV effect comes from studies using distinct entities, while evidence for the UV effect comes from studies using morphing. The reason is perhaps that Wang and colleagues cited studies our analysis excluded for not using a test statistic [Hanson et al. 2005] or for having image noise [e.g., one face with two sets of hair, Seyama \& Nagayama 2007]. In addition, several distinct entities studies with supportive results were published after their review [Brink et al. 2017; Jung \& Cho 2018; Kätsyri, de Gelder, \& Takala, 2019; Mathur \& Reichling, 2016; Mathur et al., 2020; Palomäki et al., 2018; Strait et al., 2017].

Finally, Wang, Lilienfeld, and Rochat [2015] criticize using face distortion as an independent variable because face distortion differs from human likeness. However, our review found face distortion can elicit UV-specific subjective experiences [e.g., Mäkäräinen et al., 2014]. Moreover, our meta-analysis found a significant UV effect in perceiving animal stimuli [e.g., Löffler et al., 2020; Schwind et al., 2017, 2018]. Thus, human likeness alone cannot predict the range of observed UV effects. A more encompassing DV conceptualization, like norm deviation, would predict a broader range of UV effects. However, norm deviation is not necessarily uncanny. Sometimes it enhances, rather than harms, the aesthetics [e.g., supernormal stimuli, Diel \& MacDorman, 2021].

\subsection{Dependent Variable Operationalizations}

The effect size of the uncanny valley's human side was more than double that of its nonhuman side. This difference may seem to reflect Mori's graph because the second peak is higher than the first. However, we also noted that, among all measures, positive affect produced the largest effect sizes for the human side and the smallest for the nonhuman side. Thus, another explanation is that positive affect is a poor measure of the UV effect.

Setting aside the miraculous and the extraterrestrial, people tend to perceive human beings as superior to nonhuman entities. This applies to stimuli appearing in UV experiments to date, such as robots, animals, and dolls. Perceived limitations in present-day human artifacts or other species reinforce our ingroup bias, rooted in our common identity, to privilege the human [MacDorman \& Entezari, 2015; Mitchell et al., 2011a]. Humans are often seen as more appealing, attractive, friendly, likable, pleasant, reassuring, and warm than nonhuman alternatives, not to mention more cultured, intelligent, and sociable. We can immediately see why positive affect measures are poor for measuring the UV effect because, despite how uncanny an android may appear, it will still appear more lifelike and less unfamiliar than a mechanical-looking robot of a novel design. Thus, it is important to focus on effective measures for the uncanny valley's nonhuman side: negative affect measures and positive indirect measures.

The effectiveness of negative affect measures like eerie, creepy, threatening, and disgusting align with the view that the UV effect is characterized by a distinctive experience of uncanniness rather than an overall decrease in positive affect [e.g., Ho, MacDorman, \& Pramono, 2008; Mangan, 2015; Redstone, 2013]. This negative experience may still reduce positive affect, though indirectly [Patrick \& Lavoro, 1997].

The most frequently used item was eerie [e.g., Ho \& MacDorman, 2010, 2017; Kätsyri et al. 2019]. Other negative items included creepy, disgusting, repulsive, strange, threatening, and weird. Concordantly, positive items with the largest effect sizes were nonspecific, such as interpersonal warmth items (likable, pleasant) or familiar [e.g., MacDorman \& Ishiguro 2006]. Despite a correlation 
between the UV effect and feelings of disgust [e.g., Ho, MacDorman, \& Pramono, 2008; MacDorman \& Entezari 2015], the item repulsive was nonsignificant.

Among indirect measures, dislike frequency produced the largest effect size, followed by categorization RT, like frequency, avoidance, viewing duration, preference choice, and preferential looking. Indirect measures, such as performance measures, are not without their limitations. Although some researchers use performance measures to quantify a construct related to, but distinct from, the UV effect, other researchers claim they measure the UV effect itself [e.g., Lewkowicz \& Ghazanfar 2012; Matsuda et al. 2015]. Measures like preferential looking and preference choice reflect general avoidance behavior, which could be elicited by the UV effect or by extraneous factors that must be controlled for, such as an ugly appearance or inhospitable disposition. Furthermore, most studies measuring performance omitted affect. Those that measured it tended to find a UV effect for affect but not for performance [Strait et al. 2015; Strait, Urry, \& Muentener 2019; for the opposite case, see Wang \& Rochat 2017].

These findings point to broader issues with measurement in UV research: First, many studies do not measure affect, but they should endeavor to do so insofar as it is possible. It is better to avoid relying solely on task performance measures [e.g., categorization RT, Cheetham, Suter, \& Jäncke 2011; Cheetham et al. 2013; Cheetham et al. 2014; Chen et al. 2010; Saygin et al. 2012; avoidance or preference, Lewkowicz \& Ghazanfar, 2012; Matsuda et al. 2012; Steckenfinger \& Ghazanfar 2009]. The reason is that we cannot infer affect and its influence on motivation solely from nonaffective behavior, though we can code it from displays of emotion. For example, in a study that used termination frequency to measure the UV effect, "the stimulus was boring" had a larger effect size than "the stimulus was unnerving" [Strait et al. 2015; Strait et al. 2019]. However, boring has never been considered the dependent variable in Mori's graph. In addition, task performance measures can diverge from affect measures [MacDorman \& Chattopadhyay 2016, 2017; Mathur et al. 2020]. Research should aim to validate performance measures by testing their specificity for the UV effect.

Second, although likability, pleasantness, and other nonspecific items used to measure overall affect tend to correlate with UV-specific items, they do not capture the experiential quality of the UV effect. Thus, unrelated factors could cause them to increase or decrease. This makes nonspecific items more susceptible to confounding variables. Perceptual variables that can influence stimulus evaluation include attractiveness [Ho \& MacDorman 2010, 2017; Principe \& Langlois 2011], atypical [Kätsyri et al. 2015; Strait et al. 2017], disgusting [Curtis et al. 2011], or misaligned features [MacDorman \& Chattopadhyay 2016], background [Łupkowski et al. 2019], color [Kennedy 2014; Valdez \& Mehrabian 1994], morphing artifacts [MacDorman \& Chattopadhyay 2016], realism [McDonnell et al. 2012], and size [Cesarei \& Codispoti 2006]. These variables tend to be automatic and stimulus-driven. Perceptual-cognitive variables include categorization difficulty [Cheetham et al. 2013; Yamada et al. 2013], expectation violation [Saygin et al. 2012], frequency [Burleigh \& Schoenherr 2015; Moreland \& Zajonc 1982], inhibitory devaluation [Ferrey, Burleigh, \& Fenske 2015; Weis \& Wiese 2017], and multimodal mismatch [Mitchell et al. 2011b; Tinwell et al. 2015]. Social variables include animacy [Koldewyn et al. 2014; Mäkäräinen et al. 2014], context [Jung \& Cho 2018], facial expressions [Paulus \& Wentura 2015; Tinwell et al. 2011], mind perception [Gray \& Wegner 2012], narrative structure [MacDorman 2019], outgroup membership [Hugenberg 2005], and perceived warmth or competence [MacDorman 2019]. Thus, studies should include UVspecific measures to mitigate potential confounds.

Third, even when UV-specific measures are used, they can be influenced by the flow of the interaction and its narrative structure [Dai \& MacDorman 2018]. Thus, it may be necessary to test for the UV effect before the interaction begins. 
Fourth, the UV effect is correlated with fear, anxiety, and disgust [Ho, MacDorman, \& Pramono 2008]. Thus, a UV measure should be able to discriminate UV stimuli from non-UV stimuli that elicit similar emotions. However, discriminant validity has not yet been demonstrated for a UV measure.

Fifth, regardless of the strength of a change in affect, at least three stimulus conditions are necessary to produce measurements that could fit a $U$-shaped curve-the valley part of Mori's graph. Even if those measurements fit, a dip in a measure like interpersonal warmth could occur for a myriad of reasons other than the UV effect. Thus, experimental control is vital.

Sixth, what eeriness is and which situations elicit it has not been specified precisely. Redstone [2013] proposed that eeriness is elicited when the ontological nature of a stimulus is unclear. Langer and König [2018] differentiate between eeriness (which they assert is a fear-related response to humanoid entities) and creepiness (an anxiety-related response to novel or unpredictable people or situations). However, these claims are untested. In general, UV research lacks a common definition and conceptualization of the UV effect.

\subsection{Limitations}

4.3.1 Study Exclusion. This meta-analysis excluded a wide range of impactful UV studies that were not intended to replicate a UV curve. For example, Gray and Wegner [2012] found the UV effect was elicited by the perception of a conscious machine or the philosophers' zombie (a person lacking conscious experience). Their findings were replicated by Appel and colleagues [2020]. Schein and Gray [2015] found that, among facial features, the UV effect was especially sensitive to the manipulation of the eyes. The review also excluded specific subgroups and nonhuman primates. For example, Steckenfinger and Ghazanfar [2009] found a UV effect in macaque monkeys. The meta-analysis also excluded studies on the neurophysiological correlates of the perception of humanlike appearance or behavior, which shed light on the neural mechanisms underlying the UV effect [e.g., Saygin et al. 2011; Urgen et al. 2018].

The meta-analysis excluded interaction effects for simplicity. However, these effects have elucidated the UV effect. For example, Green and colleagues [2008] found an interaction between the degree of face distortion and realism render by showing that sensitivity to acceptable facial proportions increased as the stimulus appeared more human. Similarly, Mäkäräinen and colleagues [2014] showed that the strangeness of faces with exaggerated expressions increased as faces were rendered more realistically. Both studies indicate realism increases the perceiver's sensitivity to human features. Thus, deviations from norms are more likely to be noticed and perceived as uncanny in realistic representations. Sensitivity increases with realism logistically ( $S$-shaped curve), not linearly, indicating a perceptual magnet effect [Chattopadhyay \& MacDorman 2016] like the one found for animacy [Looser and Wheatley 2010]. In a similar vein, Deska and colleagues [2017] found that the perception of a mind occurs when a face appears nearly human and is processed configurally [cf. Gray \& Wegner 2012; Tinwell et al. 2013].

Smaller studies, which require a larger effect size to obtain significance, tended to have larger effect sizes in our meta-analysis. Specifically, the average effect size of smaller studies, those in the quartile with the largest standard errors, was more than double that of the other three quartiles. Typically, inflated effect sizes in smaller studies are explained by publication bias or $p$-hacking. Publication bias results from unpublished or unreported nonsignificant effects missing from a meta-analysis, and $p$-hacking is the failure to control for multiplicity in significance testing. However, $p$-curve analysis found no signs of publication bias or $p$-hacking.

Twenty-six of 98 studies that met selection criteria, including significance testing, were excluded from the meta-analysis because they provided insufficient information to calculate effect sizes. This 
issue arose mainly for nonsignificant effect sizes. Nevertheless, the field has shown interest in nonsignificant and contrary effects, and papers reporting them have been well-cited [e.g., Cheetham et al. 2014; Thompson et al. 2011]. Because this paper focuses on comparing methodologies, bias affecting relative comparisons between effect sizes is more worrisome than bias affecting their absolute magnitude.

4.3.2 Diverse Methodologies. The diversity of UV methodologies impeded the meta-analysis. The volume of IV-DV combinations complicated the interpretation of effect sizes for creation techniques and for measures, especially for IV-DV combinations used in only a few studies. Precision in meta-regression requires having enough combinations in each cell. At least five is one rule of thumb [Borenstein et al. 2009]. However, three of ten techniques, 23 of 39 affect measures, and 12 of 14 indirect measures were used in fewer than five studies. The variety of experimental designs and other study-specific variables also complicates interpretation of the results. To draw conclusions about techniques and methods simultaneously requires enough significance tests or effect sizes to make comparisons [Lay et al. 2016]. Future research could give priority to the validation of rarely used methods.

\section{CONCLUSION}

This is the first meta-analysis on the UV effect. We used meta-regression to evaluate the methods used to operationalize the axes of Mori's graph. Our findings provide a methodological foundation for UV research. After discussing the conceptual foundations of the uncanny valley, we have presented successful research methodologies and raised methodological concerns.

\subsection{Recommendations}

We end by proposing the following design principles for stimulus creation techniques and measures in UV research:

Items that measure the UV experience as a distinct experience of uncanniness, such as uncanny and eerie, or of strangeness, such as weird or strange, are preferred to nonspecific items. They also have face validity. In this vein, negative items are preferred to positive ones. Negative items can always be reverse scaled to plot the valley.

Affect or preference measures are necessary to assess the UV effect. Although indirect measures may complement them, a study should not rely solely on indirect measures, if possible. The validity of performance measures warrants further investigation.

The stimulus creation techniques producing the largest effect sizes were face distortion, distinct entities, realism render, and morphing.

A drawback of morphing is that, if the endpoint images are too similar, the $x$-axis may not include the uncanny valley. Morphing that disrupts the configural pattern may produce a larger effect; however, it should avoid creating visual artifacts from the morphing process. How best to employ morphing is a topic for future research.

Useful stimulus creation techniques include distorting facial features, rendering at different realism levels, and using different emotional expressions. Their choice depends on theoretical considerations and the research question. Further investigation is needed on realism rendering and how it influences UV-specific negative measures compared with nonspecific positive measures.

When using distinct entities, researchers should apply standards for stimulus selection (e.g., similar size, perspective, facial expression, and lighting). The effect of stimulus standardization on the UV effect also warrants investigation. 
APPENDIX

Table A1. Indices and Cronbach's $\alpha$ 's of UV Studies

\begin{tabular}{|c|c|c|c|c|}
\hline $\begin{array}{l}\text { Authors reference } \\
\text { number [study } \\
\text { no.] }\end{array}$ & Indices: separate scales & $\begin{array}{c}\text { UV effect } \\
\text { significance? }\end{array}$ & $\begin{array}{l}\text { Cronbach's } \alpha \\
\text { per condition }\end{array}$ & $\begin{array}{l}\text { Stimulus creation } \\
\text { technique }\end{array}$ \\
\hline $\begin{array}{l}\text { Bartneck et al. } \\
\text { [2009a] }\end{array}$ & $\begin{array}{l}\text { Likability: awful-nice, unfriendly-friendly, } \\
\text { unkind-kind, and unpleasant-pleasant }\end{array}$ & No & $.92, .88, .84$ & Real-life encounter \\
\hline $\begin{array}{l}\text { Destephe et al. } \\
\text { [2015] }\end{array}$ & $\begin{array}{l}\text { Eeriness: eerie-reassuring, freaky-numbing, } \\
\text { supernatural-ordinary, } \\
\text { spine-tingling-uninspiring, thrilling-boring, } \\
\text { mortal-predictable, uncanny-bland, and } \\
\text { hair-raising-unemotional }\end{array}$ & Yes & .85 & Motion manipulation \\
\hline $\begin{array}{l}\text { Ho \& MacDorman } \\
\text { [2017] }\end{array}$ & $\begin{array}{l}\text { Eeriness: dull-freaky, predictable-eerie, } \\
\text { plain-weird, ordinary-supernatural, } \\
\text { boring-shocking, uninspiring-spine-tingling, } \\
\text { predictable-thrilling, bland-uncanny, and } \\
\text { unemotional-hair-raising }\end{array}$ & Yes & .86 & Distinct entities \\
\hline \multirow[t]{2}{*}{$\begin{array}{l}\text { Ho \& MacDorman } \\
\text { [2010] }\end{array}$} & $\begin{array}{l}\text { Eeriness: reassuring-eerie, numbing-freaky, } \\
\text { ordinary-supernatural, and } \\
\text { uninspiring-spine-tingling }\end{array}$ & Yes & .74 & Distinct entities \\
\hline & $\begin{array}{l}\text { Warmth: cold-hearted-warm-hearted, } \\
\text { hostile-friendly, spiteful-well-intentioned, } \\
\text { ill-tempered-good-natured, and grumpy-cheerful }\end{array}$ & Yes & .88 & \\
\hline \multirow{3}{*}{$\begin{array}{l}\text { Kätsyri, } \\
\text { Mäkäräinen, \& } \\
\text { Takala [2017] }\end{array}$} & Likable: likable, aesthetic, and pleasant & No & .90 & Distinct entities \\
\hline & Eerie: eerie and unsettling & No & .70 & \\
\hline & Eerie: eerie, unsettling, and strange & No & .64 & \\
\hline $\begin{array}{l}\text { Lischetzke et al. } \\
\text { [2017] }\end{array}$ & Index: creepy, eerie, and uncanny & Yes & .92 & Morphing \\
\hline \multirow{2}{*}{$\begin{array}{l}\text { MacDorman \& } \\
\text { Chattopadhyay } \\
{[2016]}\end{array}$} & $\begin{array}{l}\text { Eeriness: ordinary-creepy, plain-weird, and } \\
\text { predictable-eerie }\end{array}$ & No & N.A. & Realism render \\
\hline & $\begin{array}{l}\text { Warmth: cold-hearted-warm-hearted, } \\
\text { hostile-friendly, and grumpy-cheerful }\end{array}$ & No & N.A. & \\
\hline Mitchell et al. & Eeriness [see Ho \& MacDorman, 2010] & Yes & .70 & Visuo-auditory \\
\hline$[2011 \mathrm{~b}]$ & Warmth [see Ho \& MacDorman, 2010] & Yes & .88 & mismatch \\
\hline \multirow{4}{*}{$\begin{array}{l}\text { Rosenthal-von der } \\
\text { Pütten \& Krämer } \\
\text { [2014] }\end{array}$} & $\begin{array}{l}\text { Threatening: threatening, eerie, uncanny, } \\
\text { dominant, and harmless }\end{array}$ & Maybe & .89 & Distinct entities \\
\hline & $\begin{array}{l}\text { Likable: pleasant, likable, attractive, familiar, } \\
\text { natural, and intelligent }\end{array}$ & Maybe & .83 & \\
\hline & Submissive: incompetent, weak, and submissive & No & .66 & \\
\hline & Unfamiliar: strange and unfamiliar & No & .67 & \\
\hline \multirow[t]{2}{*}{$\begin{array}{l}\text { Schwind et al. } \\
\text { [2018] }\end{array}$} & $\begin{array}{l}\text { Familiarity: uncanny-familiar and } \\
\text { freaky-numbing }\end{array}$ & Yes & N.A. & Distinct entities (cats) \\
\hline & $\begin{array}{l}\text { Aesthetics: ugly-beautiful and } \\
\text { unaesthetic-aesthetic }\end{array}$ & Yes & N.A. & \\
\hline $\begin{array}{l}\text { Shin, Kim, \& } \\
\text { Biocca [2019] } \\
\end{array}$ & $\begin{array}{l}\text { Eeriness: reassuring-eerie, numbing-freaky, and } \\
\text { ordinary-supernatural }\end{array}$ & Yes & .76 & Realism render \\
\hline $\begin{array}{l}\text { Stein \& Ohler } \\
\text { [2018] }\end{array}$ & Eeriness (n.a.) & Yes & .74 & $\begin{array}{l}\text { Emotion } \\
\text { manipulation, face } \\
\text { distortion, realism } \\
\text { render, } \\
\text { visuo-auditory } \\
\text { mismatch } \\
\end{array}$ \\
\hline $\begin{array}{l}\text { Tinwell et al. } \\
\text { [2013] }\end{array}$ & $\begin{array}{l}\text { Uncanniness: eerie, nonhumanlike, repulsive, } \\
\text { unattractive, unlikable, and unresponsive }\end{array}$ & Yes & $.74, .80, .80$ & $\begin{array}{l}\text { Emotion } \\
\text { manipulation }\end{array}$ \\
\hline
\end{tabular}


Table A1. Continued

\begin{tabular}{|c|c|c|c|c|}
\hline $\begin{array}{l}\text { Authors } \\
\text { (reference } \\
\text { number) [study } \\
\text { no.] }\end{array}$ & Indices: separate scales & $\begin{array}{c}\text { UV effect } \\
\text { significance? }\end{array}$ & $\begin{array}{l}\text { Cronbach's } \alpha \\
\text { per condition }\end{array}$ & $\begin{array}{c}\text { Stimulus creation } \\
\text { technique }\end{array}$ \\
\hline Tung [2016] [1][2] & Social attraction: friendly, likable, and pleasant & $\begin{array}{l}\text { Yes [1] } \\
\text { No [2] }\end{array}$ & $\geq .70$ & Distinct entities \\
\hline $\begin{array}{l}\text { Złotowski et al. } \\
\text { [2015] }\end{array}$ & Eeriness (n.a.) & Yes & $\begin{array}{l}.62 \text { (lowest of } \\
\text { three mea- } \\
\text { surements) }\end{array}$ & Real-life encounter \\
\hline
\end{tabular}

Note. Eeriness and Warmth denote the indices developed by Ho and MacDorman [2010,2017] and their derivations. We did not find studies with information on correlations between individual scale items.

Table A2. Summary and Evaluation of Stimulus Creation Techniques

\begin{tabular}{|c|c|c|c|c|}
\hline $\begin{array}{l}\text { Stimulus creation } \\
\text { technique }\end{array}$ & Exemplar studies & Advantages & Disadvantages & $\begin{array}{c}\text { Further } \\
\text { considerations }\end{array}$ \\
\hline Distinct entities & $\begin{array}{l}\text { Mathur et al. } \\
{[2020]} \\
\text { Rosenthal-von } \\
\text { der Pütten \& } \\
\text { Krämer [2014] }\end{array}$ & $\begin{array}{l}\text { Relatively high } \\
\text { ecological } \\
\text { validity, variable } \\
\text { stimulus control, } \\
\text { easy access }\end{array}$ & $\begin{array}{l}\text { Confounding } \\
\text { variables, no } \\
\text { gradual range }\end{array}$ & $\begin{array}{l}\text { Additional control } \\
\text { when selecting } \\
\text { stimuli can decrease } \\
\text { confounding variables }\end{array}$ \\
\hline $\begin{array}{l}\text { Emotion } \\
\text { manipulation }\end{array}$ & $\begin{array}{l}\text { Tinwell et al. } \\
\text { [2014] }\end{array}$ & $\begin{array}{l}\text { Specific, } \\
\text { controllable } \\
\text { stimulus } \\
\text { manipulation }\end{array}$ & Stimulus noise & \\
\hline Face distortion & $\begin{array}{l}\text { Mäkäräinen } \\
\text { et al. [2014] } \\
\text { MacDorman } \\
\text { et al. [2009] }\end{array}$ & $\begin{array}{l}\text { Controllable } \\
\text { stimulus } \\
\text { manipulation, } \\
\text { gradual range }\end{array}$ & Stimulus noise & $\begin{array}{l}\text { Strength of distortion } \\
\text { should have a } \\
\text { sufficient range }\end{array}$ \\
\hline Morphing & $\begin{array}{l}\text { Lischetzke et al. } \\
\text { [2017] } \\
\text { Sasaki, Ihaya, \& } \\
\text { Yamada }\end{array}$ & $\begin{array}{l}\text { Controllable } \\
\text { stimulus } \\
\text { manipulation, } \\
\text { gradual range }\end{array}$ & $\begin{array}{l}\text { Results depend } \\
\text { on endpoint } \\
\text { stimuli choice, } \\
\text { Stimulus noise }\end{array}$ & $\begin{array}{l}\text { Endpoint stimuli } \\
\text { should be sufficiently } \\
\text { distinct }\end{array}$ \\
\hline Mismatch & $\begin{array}{l}\text { Seyama \& } \\
\text { Nagayama } \\
{[2007]}\end{array}$ & $\begin{array}{l}\text { Controllable } \\
\text { stimulus } \\
\text { manipulation }\end{array}$ & $\begin{array}{l}\text { Stimulus noise, } \\
\text { no gradual range }\end{array}$ & $\begin{array}{l}\text { Selection of } \\
\text { mismatched features } \\
\text { (e.g., eyes) } \\
\text { Lack of research }\end{array}$ \\
\hline $\begin{array}{l}\text { Motion } \\
\text { manipulation }\end{array}$ & $\begin{array}{l}\text { Handzic \& Reed } \\
\text { [2015] }\end{array}$ & & & Lack of research \\
\hline Realism render & $\begin{array}{l}\text { McDonnell et al. } \\
\text { [2012] } \\
\text { MacDorman \& } \\
\text { Chattopadhyay } \\
\text { [2017] }\end{array}$ & $\begin{array}{l}\text { Controllable } \\
\text { stimulus } \\
\text { manipulation }\end{array}$ & Stimulus noise & \\
\hline Real-life encounter & $\begin{array}{l}\text { Złotowski et al. } \\
\text { [2015] } \\
\text { Bartneck, Kanda, } \\
\text { Ishiguro, \& } \\
\text { Hagita [2009] }\end{array}$ & $\begin{array}{l}\text { High ecological } \\
\text { validity for } \\
\text { android science }\end{array}$ & $\begin{array}{l}\text { Low internal } \\
\text { validity, difficult } \\
\text { setup and } \\
\text { stimulus } \\
\text { acquisition }\end{array}$ & $\begin{array}{l}\text { Android/robotic and } \\
\text { human counterpart } \\
\text { stimuli should match } \\
\text { Lack of research }\end{array}$ \\
\hline $\begin{array}{l}\text { Visuo-auditory } \\
\text { mismatch }\end{array}$ & $\begin{array}{l}\text { Mitchell et al. } \\
\text { [2011b] }\end{array}$ & & & Lack of research \\
\hline Voice distortion & $\begin{array}{l}\text { Baird et al. } \\
{[2018]}\end{array}$ & & & Lack of research \\
\hline
\end{tabular}




\section{REFERENCES}

Markus Appel, David Izydorczyk, Silvana Weber, Martina Mara, and Tanja Lischetzke. 2020. The uncanny of mind in a machine: Humanoid robots as tools, agents, and experiencers. Computers in Human Behavior 102 (2020), 274-286. https://doi.org/10.1016/j.chb.2019.07.031

Markus Appel, Silvana Weber, Stefan Krause, and Martina Mara. 2016. On the eeriness of service robots with emotional capabilities. In The Eleventh ACM/IEEE International Conference on Human Robot Interaction. IEEE Press, 411-412.

Alice Baird, Emilia Parada-Cabaleiro, Simone Hantke, Felix Burkhardt, Nicholas Cummins, and Björn Schuller. 2018. The perception and analysis of the likeability and human likeness of synthesized speech. Proceedings of Interspeech 2018 (Sep. 2018), 2863-2867. https://doi.org/10.21437/Interspeech.2018-1093

Christoph Bartneck, Takayuki Kanda, Hiroshi Ishiguro, and Norihiro Hagita. 2009a. My robotic doppelgänger: A critical look at the uncanny valley theory. Proceedings of the 18th IEEE International Symposium on Robot and Human Interactive Communication (Nov. 2009) (RO-MAN, 269-276). Toyama, Japan. https://doi.org/10.1109/roman.2009.5326351

Christoph Bartneck, Dana Kulić, Elizabeth Croft, and Susana Zoghbi. 2009b. Measurement instruments for the anthropomorphism, animacy, likeability, perceived intelligence, and perceived safety of robots. International fournal of Social Robotics 1, 71-81. https://doi.org/10.1007/s12369-008-0001-3

Kimberley A. Brink, Kurt Gray, and Henry M. Wellman. 2017. Creepiness creeps in: Uncanny valley feelings are acquired in childhood. Child Development 90, 4 (2019), 1202-1214. https://doi.org/10.1111/cdev.12999

Michael Borenstein, Larry V. Hedges, Julian P. T. Higgins, and Hannah R. Rothstein. 2009. Introduction to Meta-analysis. Wiley, Hoboken, NJ.

Elizabeth Broadbent, Vinayak Kumar, Xingyan Li, John Sollers, III, Rebecca Q. Stafford, and Bruce A. MacDonald. 2013. Robots with display screens: A robot with a more humanlike face display is perceived to have more mind and a better personality. PLOS One 8, 8 (2013), 1-10. https://doi.org/10.1371/journal.pone.0072589

Tyler J. Burleigh and Jordan R. Schoenherr. 2015. A reappraisal of the uncanny valley: Categorical perception or frequencybased sensitization? Frontiers in Psychology, 5 (2015), 1488. https://doi.org/10.3389/fpsyg.2014.01488

Tyler J. Burleigh, Jordan R. Schoenherr, and Guy L. Lacroix. 2013. Does the uncanny valley exist? An empirical test of the relationship between eeriness and the human likeness of digitally created faces. Computers in Human Behavior 29, 3 (2013), 759-771. https://doi.org/10.1016/j.chb.2012.11.021

Colleen Carpinella, Alisa Wyman, Michael Perez, and Steven Stroessner. 2017. The robotic social attributes scale (RoSAS): Development and validation. ACM/IEEE International Conference on Human-Robot Interaction. (254-262). New York, NY, USA. https://doi.org/10.1145/2909824.3020208

Evan W. Carr, Galit Hofree, Kayla Sheldon, Ayse P. Saygin, and Piotr Winkielman. 2017. Is that a human? Categorization (dis)fluency drives evaluations of agents ambiguous on human-likeness. Journal of Experimental Psychology: Human Perception and Performance 43, 4 (2017), 651-666. https://doi.org/10.1037/xhp0000304

Andrea de Cesarei and Maurizio Codispoti. 2006. When does size not matter? Effects of stimulus size on affective modulation. Psychophysiology 43, 2 (2006), 207-215. https://doi.org/10.1111/j.1469-8986.2006.00392.x

Thierry Chaminade, Jessica K. Hodgins, and Mitsuo Kawato. 2007. Anthropomorphism influences perception of computeranimated characters' actions (Sep. 2007). Social Cognitive and Affective Neuroscience 2, 3 (2007), 206-216. https://doi.org/ 10.1111/j.1469-8986.2006.00392.x

Debaleena Chattopadhyay and Karl F. MacDorman. 2016. Familiar faces rendered strange: Why inconsistent realism drives characters into the uncanny valley (Sep. 2016). Journal of Vision, 16, 11:7, 1-25. https://doi.org/10.1167/16.11.7

Marcus Cheetham and Lutz Jäncke. 2013. Perceptual and category processing of the uncanny valley hypothesis' dimension of human likeness (Jun. 2013): Some methodological issues. Fournal of Visualized Experiments 76, 4375. https://doi.org/ $10.3791 / 4375$

Marcus Cheetham, Ivana Pavlović, Nicola J. Jordan, Pascal Suter, and Lutz Jäncke. 2013. Category processing and the human likeness dimension of the uncanny valley hypothesis: Eye-tracking data. Frontiers in Psychology 4, 108. https: //doi.org/10.3389/fpsyg.2013.00108

Marcus Cheetham, Pascal Suter, and Lutz Jäncke. 2011. The human likeness dimension of the "uncanny valley hypothesis": Behavioral and functional MRI findings (2011). Frontiers in Human Neuroscience 5, 125 (2011), 126. https://doi.org/10. 3389/fnhum.2011.00126

Marcus Cheetham, Pascal Suter, and Lutz Jäncke. 2014. Perceptual discrimination difficulty and familiarity in the uncanny valley: More like a "happy valley". Frontiers in Psychology 5 (2014), 1219. https://doi.org/10.3389/fpsyg.2014.01219

Marcus Cheetham, Lingdan D. Wu, Paul Pauli, and Lutz Jäncke. 2015. Arousal, valence, and the uncanny valley: Psychophysiological and self-report findings. Frontiers in Psychology 6 (2015), 981. https://doi.org/10.3389/fpsyg.2015.00981

Haiwen Chen, Richard Russell, Ken Nakayama, and Margaret Livingstone. 2010. Crossing the 'uncanny valley': Adaptation to cartoon faces can influence perception of human faces. Perception 39, 3 (2010), 378-386. https://doi.org/10.1068/p6492

Mike W.-L. Cheung. 2019. A guide to conducting a meta-analysis with non-independent effect sizes. Neuropsychology Review 29 (2019), 387-396. https://doi.org/10.1007/s11065-019-09415-6 
Leon Ciechanowski, Aleksandra Przegalińska, Mikolaj Magnuski, and Peter Gloor. 2019. In the shades of the uncanny valley: An experimental study of human-chatbot interaction. Future Generation Computer Systems 92 (2019), 539-548. https://doi.org/10.1016/j.future.2018.01.055

Jacob Cohen. 1988. Statistical Power Analysis for the Behavioral Sciences (2nd ed). Lawrence Erlbaum Associates, Hillsdale, New Jersey.

Valerie Curtis, Mícheál de Barra, and Robert Aunger. 2011. Disgust as an adaptive system for disease avoidance behavior. Philosophical Transactions of the Royal Society B: Biological Sciences 366 (2011), 389-401. https://doi.org/10.1098/rstb. 2010.0117

Zhengyan Dai and Karl F. MacDorman. 2018. The doctor's digital double: How warmth, competence, and animation promote adherence intention. Peerf Computer Science, 4 (2018), e168, 1-29. https://doi.org/10.7717/peerj-cs.168

Jason C. Deska, Steven M. Almaraz, and Kurt Hugenberg. 2017. Of mannequins and men: Ascriptions of mind in faces are bounded by perceptual and processing similarities to human faces. Social Psychological and Personality Science 8, 2 (2016), 183-190. https://doi.org/10.1177/1948550616671404

Matthieu Destephe, Massimiliano Zecca, Kenji Hashimoto, and Atsuo Takanishi. 2014. Uncanny valley, robot and autism: Perception of the uncanniness in an emotional gait. Proceedings of the IEEE International Conference on Robotics and Biomimetics (1152-1157), Bali, Indonesia, 2014. https://doi.org/10.1109/ROBIO.2014.7090488.

Matthieu Destephe, Martim Brandao, Tatsuhiro Kishi, Massimiliano Zecca, Kenji Hashimoto, and Atsuo Takanishi. 2015. Walking in the uncanny valley: Importance of the attractiveness on the acceptance of a robot as a working partner. Frontiers in Psychology 6 (2015), 204. https://doi.org/10.3389/fpsyg.2015.00204

Alexander Diel and Karl F. MacDorman. 2021. Creepy cats and strange high houses: Support for configural processing in testing predictions of nine uncanny valley theories. Fournal of Vision 21, 4 (2021), 1-20. DOI : https://doi.org/10.1167/jov. 21.4 .1

Shuyuan Feng, Xueqin Wang, Qiandong Wang, Jing Fang, Yaxue Wu, Li Yi, and Kunlin Wei. 2018. The uncanny valley effect in typically developing children and its absence in children with autism spectrum disorders. PLOS ONE 13 (2018), e0206343. https://doi.org/10.1371/journal.pone.0206343

Francesco Ferrari, Maria Paola Paladino, and Jolanda Jetten. 2016. Blurring human-machine distinctions: Anthropomorphic appearance in social robots as a threat to human distinctiveness. International fournal of Social Robotics 8, 2 (2016), 287-302. https://10.1007/s12369-016-0338-y

Anne E. Ferrey, Tyler J. Burleigh, and Mark J. Fenske. 2015. Stimulus-category competition, inhibition, and affective devaluation: A novel account of the uncanny valley. Frontiers in Psychology 6 (2015), 249. https://doi.org/10.3389/fpsyg.2015. 00249

Susan T. Fiske, Amy J. C. Cuddy, and Peter Glick. 2007. Universal dimensions of social cognition: Warmth and competence. Trends in Cognitive Sciences 11 (2007), 77-83. https://doi.org/10.1016/j.tics.2006.11.005

Susan T. Fiske, Amy J. C. Cuddy, Peter Glick, and Jun Xu. 2002. A model of (often mixed) stereotype content: Competence and warmth respectively follow from perceived status and competition. fournal of Personality and Social Psychology 82 (2002), 878-902. https://doi.org/10.1037/0022-3514.82.6.878

Rasmus Gahrn-Andersen. 2020. Seeming autonomy, technology and the uncanny valley. AI \& Society (2020). https://doi. org/10.1007/s00146-020-01040-9

Kurt Gray and Daniel M. Wegner. 2012. Feeling robots and human zombies: Mind perception and the uncanny valley. Cognition 125 (2012), 125-130. https://doi.org/10.1016/j.cognition.2012.06.007

Robert D. Green, Karl F. MacDorman, Chin-Chang Ho, and Sandosh K. Vasudevan. 2008. Sensitivity to the proportions of faces that vary in human likeness. Computers in Human Behavior 24, 5 (2008), 2456-2474. https://doi.org/10.1016/j.chb. 2008.02.019

Sigmund Freud. 1919/2003. The uncanny [das Unheimliche] (D. McClintock, Trans.). Penguin, New York.

Ismet Handzic and Kyle B. Reed. 2015. Perception of gait patterns that deviate from normal and symmetric biped locomotion. Frontiers in Psychology 6 (2015). https://doi.org/10.3389/fpsyg.2015.00199

David Hanson, Andrew Olney, Steve Prilliman, Eric Mathews, Marge Zielke, Derek Hammons, Raul Fernandez, and Harry E. Stephanou. 2005. Upending the uncanny valley. Proceedings of the Twentieth National Conference on Artificial Intelligence (2005), 1728-1729. AAAI Press, Menlo Park, CA.

Russell Hardin. 2002. Trust and Trustworthiness. Russell Sage Foundation, New York, NY.

Chin-Chang Ho, and Karl F. MacDorman. 2010. Revisiting the uncanny valley theory: Developing and validating an alternative to the Godspeed indices. Computers in Human Behavior 26 (2010), 1508-1518. https://doi.org/10.1016/j.chb.2010. 05.015

Chin-Chang Ho and Karl F. MacDorman. 2017. Measuring the uncanny valley effect: Refinements to indices for perceived humanness, attractiveness, and eeriness. International fournal of Social Robotics 9 (2017), 129-139. https://doi.org/10. 1007/s12369-016-0380-9 
Chin-Chang Ho, Karl F. MacDorman, and Zacharias A. D. Pramono. 2008. Human emotion and the uncanny valley: A GLM, MDS, and ISOMAP analysis of robot video ratings. Proceedings of the Third ACM/IEEE International Conference on Human-Robot Interaction (2008), 169-176, March 11-14, 2008. Amsterdam, Netherlands. https://doi.org/10.1145/1349822. 1349845

Kurt Hugenberg. 2005. Social categorization and the perception of facial affect: Target race moderates the response latency advantage for happy faces. Emotion 5, 3 (2005), 267-276. https://doi.org/10.1037/1528-3542.5.3.267

Yoonhyuk Jung and Eunae Cho. 2018. Context-specific affective and cognitive responses to humanoid robots. Proceedings of the 22nd ITS Biennial Conference, Beyond the Boundaries: Challenges for Business, Policy and Society (2018). International Telecommunications Society (ITS). Seoul, Korea.

Hiroko Kamide, Koji Kawabe, Satoshi Shigemi, and Tatsuo Arai. 2013. Development of a psychological scale for general impressions of humanoid. Advanced Robotics 27, 1 (2013), 3-17, https://doi.org/10.1080/01691864.2013.751159

Jari Kätsyri. 2018. Those virtual people all look the same to me: Computer-rendered faces elicit a higher false alarm rate than real human faces in a recognition memory task. Frontiers in Psychology 9, 1362. https://doi.org/10.3389/fpsyg.2018.01362

Jari Kätsyri, Beatrice de Gelder, and Apio Takala. 2019. Virtual faces evoke only a weak uncanny valley effect: An empirical investigation with controlled virtual face images. Perception 48, 10 (2019), 968-991. https://doi.org/10.1177/ 0301006619869134

Jari Kätsyri, Klaus Förger, Meeri Mäkäräinen, and Tapio Takala. 2015. A review of empirical evidence on different uncanny valley hypotheses: Support for perceptual mismatch as one road to the valley of eeriness. Frontiers in Psychology 6 (2015), 390. https://doi.org/10.3389/fpsyg.2015.00390

Jari Kätsyri, Meeri Mäkäräinen, and Tapio Takala. 2017. Testing the 'uncanny valley' hypothesis in semirealistic computeranimated film characters: An empirical evaluation of natural film stimuli. International fournal of Human-Computer Studies 97 (2017), 149-161. https://doi.org/10.1016/j.ijhcs.2016.09.010.

Andrew Kennedy. 2014. The Effect of Color on Emotions in Animated Films. Open Access Theses, 201 (2014). https://docs.lib. purdue.edu/open_access_theses/201

Marino Kimura and Yuko Yotsumoto. 2018. Auditory traits of “own voice.” PLOS One 13, 6 (2016), Article e0199443. https: //doi.org/10.1371/journal.pone.0199443

Kami Koldewyn, Patricia Hanus, and Benjamin Balas. 2014. Visual adaptation of the perception of "life": Animacy is a basic perceptual dimension of faces. Psychonomic Bulletin and Review 21, 4 (2014), 969-975. https://doi.org/10.3758/s13423013-0562-5

Genevieve M. Kozak, Megan L. Head, Alycia C. R. Lackey, and Janette W. Boughman. 2013. Sequential mate choice and sexual isolation in threespine stickleback species. Journal of Evolutionary Biology 261 (2013), 130-140. https://doi.org/ 10.1111/jeb.12034

Katharina Kühne, Martin H. Fischer, and Yuefang Zhou. 2020. The human takes it all: Humanlike synthesized voices are perceived as less eerie and more likable: Evidence from a subjective ratings study. Frontiers in Neurorobotics 14:593732. https://doi.org/10.3389/fnbot.2020.593732

Oliver Langner, Ron Dotsch, Gijsbert Bijlstra, Daniel H. J. Wigboldus, Skyler T. Hawk, and Ad van Knippenberg. 2010. Presentation and validation of the Radboud faces database. Cognition \& Emotion 24, 8 (2010), 1377-1388. https://doi. org $/ 10.1080 / 02699930903485076$

Markus Langer and Cornelius J. König. 2018. Introducing and testing the creepiness of situation scale (CRoSS). Frontiers in Psychology 9 (2018), 2220. https://doi.org/10.3389/fpsyg.2018.02220

Stephanie Lay, Nicola Brace, Graham Pike, and Frank Pollick. 2016. Circling around the uncanny valley: Design principles for research into the relation between human likeness and eeriness. i-Perception 7, 6 (2016), 1-11. https://doi.org/10. 1177/2041669516681309

David J. Lewkowicz and Asif A. Ghazanfar. 2012. The development of the uncanny valley in infants. Developmental Psychobiology 54, 2 (2012), 124-132. https://doi.org/10.1002/dev.20583

Chaolan Lin, Selma Šabanović, Lynn Dombrowski, Andrew D. Miller, Erin Brady and Karl F. MacDorman. 2021. Parental acceptance of children's storytelling robots: A projection of the uncanny valley of AI. Frontiers in Robotics and AI 8 (2021), 579993, 1-15. https://doi.org/10.3389/frobt.2021.579993

Tanja Lischetzke, David Izydorczyk, Christina Hüller, and Markus Appel. 2017. The topography of the uncanny valley and individuals' need for structure: A nonlinear mixed effects analysis. Journal of Research in Personality 68 (2011) 96-113. https://doi.org/10.1016/j.jrp.2017.02.001

Lukasz Piwek, Lawrie S. McKay, and Frank E. Pollick. 2014. Empirical evaluation of the uncanny valley hypothesis fails to confirm the predicted effect of motion. Cognition 130, 3 (2014), 271-277. https://doi.org/10.1016/j.cognition.2013.11.001

Diana Löffler, Judith Dörrenbächer, and Marc Hassenzahl. 2020. The uncanny valley effect in zoomorphic robots: The $U$ shaped relation between animal likeness and likeability. In Proceedings of the 2020 ACM/IEEE International Conference on Human-Robot Interaction (261-270). ACM, New York, NY. https://doi.org/10.1145/3319502.3374788

Christine E. Looser and Thalia Wheatley. 2010. The tipping point of animacy: How, when, and where we perceive life in a face. Psychological Science 21, 12 (2010), 1854-1862. https://doi.org/10.1177/0956797610388044

ACM Transactions on Human-Robot Interaction, Vol. 11, No. 1, Article 1. Publication date: October 2021. 
Paweł Łupkowski, Marek Rybka, Dagmara Dziedzic, and Wojciech Włodarczyk. 2019. The background context condition for the uncanny valley hypothesis. International fournal of Social Robotics 11 (2018), 25-33. https://doi.org/10.1007/s12369018-0490-7

Goh Matsuda, Hiroshi Ishiguro, and Kazuo Hiraki. 2015. Infant discrimination of humanoid robots. Frontiers in Psychology 6 (2015), 1397. https://doi.org/10.3389/fpsyg.2015.01397

Yoshi-Taka Matsuda, Yoko Okamoto, Misako Ida, Kazuo Okanoya, and Masako Myowa-Yamakoshi. 2012. Infants prefer the faces of strangers or mothers to morphed faces: An uncanny valley between social novelty and familiarity. Biology Letters 8 (2012), 725-728. https://10.1098/rsbl.2012.0346

Karl F. MacDorman and Debaleena Chattopadhyay. 2016. Reducing consistency in human realism increases the uncanny valley effect; increasing category uncertainty does not. Cognition 146 (2016), 190-205. https://doi.org/10.1016/ j.cognition.2015.09.019

Karl F. MacDorman and Debaleena Chattopadhyay. 2017. Categorization-based stranger avoidance does not explain the uncanny valley. Cognition 161 (2017), 129-135. https://doi.org/10.1016/j.cognition.2017.01.009

Karl F. MacDorman and Steven O. Entezari. 2015. Individual differences predict sensitivity to the uncanny valley. Interaction Studies 16, 2 (2015), 141-172. https://doi.org/10.1075/is.16.2.01mac

Karl F. MacDorman, Robert D. Green, Chin-Chang Ho, and Clinton T. Koch. 2009. Too real for comfort? Uncanny responses to computer generated faces. Computers in Human Behavior 25, 3 (2014), 695-710. https://doi.org/10.1016/j.chb.2008.12. 026

Karl F. MacDorman and Hiroshi Ishiguro. 2006. The uncanny advantage of using androids in cognitive and social science research. Interaction Studies 7, 3 (2006), 297-337. https://doi.org/10.1075/is.7.3.03mac

Karl F. MacDorman, Takashi Minato, Michihiro Shimada, Shoji Itakura, Stephen Cowley, and Hiroshi Ishiguro. 2005. Assessing human likeness by eye contact in an android testbed. Proceedings of the XXVII Annual Meeting of the Cognitive Science Society (2005), 1373-1378.

Karl F. MacDorman, Preethi Srinivas, and Himalaya Patel. 2013. The uncanny valley does not interfere with level 1 visual perspective taking. Computers in Human Behavior 29, 4 (2013), 1671-1685. https://doi.org/10.1016/j.chb.2013.01.051

Meeri Mäkäräinen, Jari Kätsyri, and Tapio Takala. 2014. Exaggerating facial expressions: A way to intensify emotion or a way to the uncanny valley? Cognitive Computation 6, 4 (2014), 708-721. https://doi.org/10.1007/s12559-014-9273-0

Bruce Mangan. 2015. The uncanny valley as fringe experience. Interaction Studies 16, 2 (2015), 193-199. https://doi.org/10. 1075/is.16.2.05man

Maya B. Mathur and David B. Reichling. 2016. Navigating a social world with robot partners: A quantitative cartography of the uncanny valley. Cognition 146 (2016), 22-32. https://doi.org/10.1016/j.cognition.2015.09.008

Maya B. Mathur, David B. Reichling, Francesca Lunardini, Alice Geminiani, Alberto Antonietti, Peter A. M. Ruijten, Carmel A. Levitan, Gideon Nave, Dylan Mafredi, Brandy Bessette-Symons, Attila Szuts, and Balazs Aczel. 2020. Uncanny but not confusing: Multisite study of perceptual category confusion in the uncanny valley. Computers in Human Behavior, 103 (2020), 21-30. https://doi.org/10.1016/j.chb.2019.08.029

Koh Matsuda, Hiroshi Ishiguro, and Kazuo Hiraki. 2015. Infant discrimination of humanoid robots. Frontiers in Psychology 6, 1397. https://doi.org/10.3389/fpsyg.2015.01397

Yoshi-Taka Matsuda, Yoko Okamoto, Misako Ida, Kazuo Okanoya, and Masako Myowa-Yamakoshi. 2012. Infants prefer the faces of strangers or mothers to morphed faces: An uncanny valley between social novelty and familiarity. Biology Letters 8, 5 (2012), 725-728. https://doi.org/10.1098/rsbl.2012.0346

Francis T. McAndrew and Sara S. Koehnke. 2016. On the nature of creepiness. New Ideas in Psychology 43 (2016), 10-15. https://doi.org/10.1016/j.newideapsych.2016.03.003

Rachel McDonnell and Martin Breidt. 2010. Face reality: Investigating the uncanny valley for virtual faces. In Marie-Paule Cani and Alla Sheffer (Eds.), ACM SIGGRAPH Asia Sketches (2010), 1-2. ACM Press, New York, NY, USA.

Rachel McDonnell, Martin Breidt, and Heinrich H. Bülthoff. 2012. Render me real? Investigating the effect of render style on the perception of animated virtual humans. ACM Transactions on Graphics 31 (2012), 1-11. https://doi.org/10.1145/ 2185520.2185587

Lianne F. S. Meah and Roger K. Moore. 2014. The uncanny valley: A focus on misaligned cues. In Michael Beetz, Benjamin Johnston, \& Mary-Anne Williams (Eds.), Social Robotics: 6th International Conference (2014), 256-265. ICSR Proceedings. Sydney, NSW, Australia. October 27-29.

Wade J. Mitchell, Chin-Chang Ho, Himalaya Patel, and Karl F. MacDorman. 2011a. Does social desirability bias favor humans? Explicit-implicit evaluations of synthesized speech support a new HCI model of impression management. Computers in Human Behavior 27, 1 (2011), 402-412. https://doi.org/10.1016/j.chb.2010.09.002

Wade J. Mitchell, Kevin A. Szerszen, Amy Shirong Lu, Paul W. Schermerhorn, Matthias Scheutz, and Karl F. MacDorman. 2011b. A mismatch in the human realism of face and voice produces an uncanny valley. i-Perception 2, 1 (2011), 10-12. https://doi.org/10.1068/i0415 
Roger K. Moore. 2012. A Bayesian explanation of the 'uncanny valley' effect and related psychological phenomena. Scientific Reports 2 (2012), 864. https://doi.org/10.1038/srep00864

Mahdi Muhammad Moosa and S. M. Minhaz Ud-Dean. 2010. Danger avoidance: An evolutionary explanation of uncanny valley. Biology Theory 5 (2010), 12-14. https://doi.org/10.1162/BIOT_a_00016

Richard L. Moreland and Robert B. Zajonc. 1982. Exposure effects in person perception: Familiarity, similarity, and attraction. Fournal of Experimental Social Psychology 18, 5 (1980), 395-415. https://doi.org/10.1016/0022-1031(82)90062-2

Masahiro Mori. 2012. The uncanny valley (Karl F. MacDorman \& Norri Kageki, Trans.). IEEE Robotics and Automation 19, 2 (2012), 98-100. (Original work published in 1970). https://doi.org/10.1109/MRA.2012.2192811

Vicneas Muniady and Ahmad Zamzuri Mohamad Ali. 2020. The effect of valence and arousal on virtual agent's designs in quiz based multimedia learning environment. International fournal of Instruction 13, 4 (2020), 903-920. https://doi.org/ 10.29333/iji.2020.13455a

Hiroshi Nitta and Kazuhide Hashiya. 2021. Self-face perception in 12-month-old infants: A study using the morphing technique. Infant Behavior and Development 62 (2021), 101479. https://doi.org/10.1016/j.infbeh.2020.101479

Iroju Olaronke, Oluwaseun A. Ojerinde, and Rhoda Ikono. 2017. State of the art: A study of human-robot interaction in healthcare. International fournal of Information Engineering \& Electronic Business 9, 3 (2017), 43-55. https://doi.org/10. 5815/ijieeb.2017.03.06

Maike Paetzel, Christopher E. Peters, Ingela Nyström, and Ginevra Castellano. 2016. Effects of multimodal cues on children's perception of uncanniness in a social robot. In Proceedings of the 18th ACM International Conference on Multimodal Interaction (2016), 297-301. Association for Computing Machinery. https://doi.org/10.1145/2993148.2993157

Jussi P. Palomäki, Anton Kunnari, Marianna Drosinou, Mika Koverola, Noora Lehtonen, Juho Halonen, Marko Repi, and Michael Laakasuo. 2018. Evaluating the replicability of the uncanny valley effect. Heliyon 4, 11 (2018). https://doi.org/ 10.1016/j.heliyon.2018.e00939

Christopher J. Patrick and Stacey A. Lavoro. 1997. Ratings of emotional response to pictorial stimuli: Positive and negative affect dimensions. Motivation and Emotion 21 (1997), 297-321. https://doi.org/10.1023/A:1024432322584

Andrea Paulus and Dirk Wentura. 2015. It depends: Approach and avoidance reactions to emotional expressions are influenced by the contrast emotions presented in the task. Journal of Experimental Psychology: Human Perception and Performance 42, 2 (2015), 197-212. https://doi.org/10.1037/xhp0000130

Jaime Alvarez Perez, Hideki Garcia Goo, Ana Sánchez Ramos, Virginia Contreras, and Megan Strait. 2020. Companion of the 2020 ACM/IEEE International Conference on Human-Robot Interaction (101-103), 2020. https://doi.org/10.1145/3371382. 3378312

Lukasz Piwek, Lawrie S. McKay, and Frank E. Pollick. 2014. Empirical evaluation of the uncanny valley hypothesis fails to confirm the predicted effect of motion. Cognition 130 (2014), 271-277. https://doi.org/10.1016/j.cognition.2013.11.001

Ellen Poliakoff, Natalie Beach, Rebecca Best, Toby Howard, and Emma Gowen. 2013. Can looking at a hand make your skin crawl? Peering into the uncanny valley for hands. Perception 42, 9 (2015), 998-1000. https://doi.org/10.1068/p7569

Akanaksha Prakash and Wendy A. Rogers. 2015. Why some humanoid faces are perceived more positively than others: Effects of human-likeness and task. International fournal of Social Robotics 7, 2, 309-331. https://doi.org/10.1007/s12369014-0269-4

Connor P. Principe and Judith H. Langlois. 2011. Faces differing in attractiveness elicit corresponding affective responses. Cognition \& Emotion 25, 1 (2011), 140-148. https://doi.org/10.1080/02699931003612098

Si Qiao and Roger Eglin. 2011. Accurate behaviour and believability of computer generated images of human head. Proceedings of the 10th International Conference on Virtual Reality Continuum and Its Applications in Industry (545-548), December 2011. https://doi.org/10.1145/2087756.2087860

Si Qiao, Roger Eglin, and Ariel Beck. 2011. Audience perception of computer generated human facial behaviour. GSTF International fournal on Computing 1, 3 (2011), 61-65.

Christopher H. Ramey. 2005. The uncanny valley of similarities concerning abortion, baldness, heaps of sand, and humanlike robots. In Proceedings of Views of the Uncanny Valley Workshop: IEEE-RAS International Conference on Humanoid Robots (2005), 8-13. Tsukuba, Japan.

Alexandra S. Rativa, Marie Postma, and Menno van Zaanen. 2019. The uncanny valley of the virtual (animal) robot. In Munir Merdan, Wilfried Lepuschitz, Gottfried Koppensteiner, Richard Balogh, and David Obdržálek (Eds.), Robotics in Education. RiE 2019. Advances in Intelligent Systems and Computing, vol. 1023. Springer, Cham. https://doi.org/10.1007/ 978-3-030-26945-6_38

Josh D. Redstone. 2013. Beyond the uncanny valley: A theory of eeriness for android science research. Master's thesis. https://doi.org/10.22215/etd/2013-09987

Jasia Reichardt. 1978. Human reactions to imitation humans, or Masahiro Mori's uncanny valley. In Jasia Reichardt, Robots: Fact, Fiction, and Prediction (1st ed., 26-27). Viking, New York. 
Anne Reuten, Maureen van Dam, and Marnix Naber. 2018. Pupillary responses to robotic and human emotions: The uncanny valley and media equation confirmed. Frontiers in Psychology 23, 9 (2018), 774. https://doi.org/10.3389/fpsyg.2018. 00774

Astrid M. Rosenthal-von der Pütten and Nicole C. Krämer. 2014. How design characteristics of robots determine evaluation and uncanny valley related responses. Computers in Human Behavior 36 (2014), 422-439. https://doi.org/10.1016/j.chb. 2014.03.066

Astrid M. Rosenthal-von der Pütten, Nicole Krämer, Stefan Maderwald, Matthias Brand, and Fabian Grabenhorst. 2019. Neural mechanisms for accepting and rejecting artificial social partners in the uncanny valley. The fournal of Neuroscience 39, 33 (2019), 6555-6570. https://doi.org/10.1523/JNEUROSCI.2956-18.2019

Nicholas Royle. 2003. The Uncanny: An Introduction. Manchester University Press, New York, NY.

Stefania Sansoni, Andrew Wodehouse, Angus K. McFadyen, and Arjan Buis. 2015. The aesthetic appeal of prosthetic limbs and the uncanny valley: The role of personal characteristics in attraction. International fournal of Design 9, 67-81.

Kyoshiro Sasaki, Keiko Ihaya, and Yuki Yamada. 2017. Avoidance of novelty contributes to the uncanny valley. Frontiers in Psychology 8 (2018), 1792. https://doi.org/10.3389/fpsyg.2017.01792

Ayse Pinar Saygin, Thierry Chaminade, Hiroshi Ishiguro, Jon Driver, and Chris Frith. 2012. The thing that should not be: Predictive coding and the uncanny valley in perceiving human and humanoid robot actions. Social Cognitive and Affective Neuroscience 7, 4 (2011), 413-422. https://doi.org/10.1093/scan/nsr025

Sebastian Schindler, Eduard Zell, Mario Botsch, and Johanna Kissler. 2017. Differential effects of face-realism and emotion on event-related brain potentials and their implications for the uncanny valley theory. Scientific Reports 7 (2017), 45003. https://doi.org/10.1038/srep45003

Edward Schneider, Yifan Wang, and Shanshan Yang. 2009. Exploring the uncanny valley with Japanese video game characters. In Baba Akira (Ed.), Proceedings of the Digital Games Research Association (DiGRA): Situated Play (2017), 546-549.

Jordan Schoenherr and Tyler J. Burleigh. 2015. Uncanny sociocultural categories. Frontiers in Psychology 5 (2015), 1456. https://doi.org/10.3389/fpsyg.2014.01456

Valentin Schwind, Pascal Knierim, Cagri Tasci, Patrick Franczak, Nico Haas, and Niels Henze. 2017. Proceedings of the 2017 CHI Conference on Human Factors in Computing Systems, May 2017, 1577-1582. https://doi.org/10.1145/3025453.3025602

Valentin Schwind, Katharina Leicht, Solveigh Jäger, Katrin Wolf, and Niels Henze. 2018. Is there an uncanny valley of virtual animals? A quantitative and qualitative investigation. International fournal of Human-Computer Studies 111 (2018), 49-61. https://doi.org/10.1016/j.ijhcs.2017.11.003

Jun'ichiro Seyama and Ruth S. Nagayama. 2007. The uncanny valley: Effect of realism on the impression of artificial human faces. Presence: Teleoperators and Virtual Environments 16 (2007), 337-351. https://doi.org/10.1162/pres.16.4.337

Mincheol Shin, Se Jung Kim, and Frank Biocca. 2019. The uncanny valley: No need for any further judgments when an avatar looks eerie. Computers in Human Behavior 94 (2019), 100-109. https://doi.org/10.1016/j.chb.2019.01.016

Mincheol Shin, Stephen W. Song, and Tamara M. Chock. 2019. Uncanny valley effects on friendship decisions in virtual social networking service. Cyberpsychology, Behavior, and Social Networking 22, 11 (2019), 700-705. https://doi.org/10. 1089/cyber.2019.0122

Jacqueline C. Snow, Rafal M. Skiba, Taylor L. Coleman, and Marian E. Berryhill. 2014. Real-world objects are more memorable than photographs of objects. Frontiers in Human Neuroscience 8, 837. https://doi.org/10.3389/fnhum.2014.00837

Shawn A. Steckenfinger and Asif A. Ghazanfar. 2009. Monkey visual behavior falls into the uncanny valley. Proceedings of the National Academy of Sciences of the United States of America (PNAS) 106, 43 (2009), 18362-18366. https://doi.org/10. 1073/pnas.0910063106

Jan-Philipp Stein and Peter Ohler. 2017. Venturing into the uncanny valley of mind-The influence of mind attribution on the acceptance of human-like characters in a virtual reality setting. Cognition 160 (2017), 43-50. https://doi.org/10.1016/ j.cognition.2016.12.010

Jan-Philipp Stein and Peter Ohler. 2018. Uncanny... but convincing? Inconsistency between a virtual agent's facial proportions and vocal realism reduces its credibility and attractiveness, but not its persuasive success. Interacting With Computers 30 (2018), 480-491. https://doi.org/10.1093/iwc/iwy023

Megan K. Strait, Victoria A. Floerke, Wendy Ju, Keith Maddox, Jessica D. Remédios, Malte F. Jung, and Heather L. Urry. 2017. Understanding the uncanny: Both atypical features and category ambiguity provoke aversion toward humanlike robots. Frontiers in Psychology 8 (2017), 1366. https://doi.org/10.3389/fpsyg.2017.01366

Megan Strait and Matthias Scheutz. 2014. Measuring users' responses to humans, robots, and human-like robots with functional near infrared spectroscopy. The 23rd IEEE International Symposium on Robot and Human Interactive Communication (2014), 1128-1133. https://doi.org/10.1145/2702123.2702415

Megan Strait, Lara Vujovic, Victoria Floerke, Matthias Scheutz, and Heather L. Urry. 2015. Too much humanness for human-robot interaction: Exposure to highly humanlike robots elicits aversive responding in observers. Proceedings of the 33rd Annual ACM Conference on Human Factors in Computing Systems (2015), 3593-3602. Seoul, Republic of Korea. https://doi.org/10.1145/2702123.2702415 
Megan Strait, Heather L. Urry, and Paul Muentener. 2019. Children's responding to humanlike agents reflects an uncanny valley. In Proceedings of the 14th ACM/IEEE International Conference on Human-Robot Interaction (2019), 506-515. https: //doi.org/10.1109/HRI.2019.8673088

Kohske Takahashi, Haruaki Fukuda, Kazuyuki Samejima, Katsumi Watanabe, and Kazuhiro Ueda. 2015. Impact of stimulus uncanniness on speeded response. Frontiers in Psychology 6 (2015), 662. https://doi.org/10.3389/fpsyg.2015.00662

James C. Thompson, J. Gregory Trafton, and Patrick McKnight. 2011. The perception of humanness from the movements of synthetic agents. Perception 40, 6 (2011), 695-704. https://doi.org/10.1068/p6900

Angela Tinwell. 2009. Uncanny as usability obstacle. In A. Ant Ozok and Panayiotis Zaphiris (Eds.), Online Communities and Social Computing. Lecture Notes in Computer Science, 5621 (2009). Springer, Berlin. https://doi.org/10.1007/978-3642-02774-1_67

Angela Tinwell, Mark N. Grimshaw, and Deborah A. Nabi. 2015. The effect of onset asynchrony in audio-visual speech and the uncanny valley in virtual characters. International fournal of Mechanisms and Robotic Systems 2, 2 (2015), 97-110. https://doi.org/10.1504/IJMRS.2015.068991

Angela Tinwell, Mark N. Grimshaw, and Deborah A. Nabi. 2014. The uncanny valley and nonverbal communication in virtual characters. In Theresa Jean Tanenbaum, Magy Seif el-Nasr, \& Michael Nixon (Eds.), Nonverbal Communication in Virtual Worlds: Understanding and Designing Expressive Characters (2014), 325-341. Carnegie Mellon University Press, Pittsburgh, PA.

Angela Tinwell, Mark N. Grimshaw, Deborah A. Nabi, and Andrew Williams. 2011. Facial expression of emotion and perception of the uncanny valley in virtual characters. Computers in Human Behavior 2 (2010), 741-749. https://doi.org/ 10.1016/j.chb.2010.10.018

Angela Tinwell, Deborah A. Nabi, and John P. Charlton. 2013. Perception of psychopathy and the uncanny valley in virtual characters. Computers in Human Behavior 29, 4 (2013), 1617-1625. https://doi.org/10.1016/j.chb.2013.01.008

Angela Tinwell and Robin J. S. Sloan. 2014. Children's perception of uncanny human-like virtual characters. Computers in Human Behavior 36 (2014), 286-296. https://doi.org/10.1016/j.chb.2014.03.073

Fangwu Tung. 2016. Child perception of humanoid robot appearance and behavior. International fournal of HumanComputer Interaction 32 (2016), 493-502. https://doi.org/10.1080/10447318.2016.1172808

Burcu A. Urgen, Marta Kutas, and Ayse P. Saygin. 2018. Uncanny valley as a window into predictive processing in the social brain. Neuropsychologia 114, 181-185. https://doi.org/10.1016/j.neuropsychologia.2018.04.027

Patricia Valdez and Albert Mehrabian. 1994. Effects of color on emotions. fournal of Experimental Psychology: General 123, 4 (2015), 394-409. https://doi.org/10.1037/0096-3445.123.4.394

Wolfgang Viechtbauer and Mike W.-L. Cheung. 2010. Outlier and influence diagnostics for meta-analysis. Research Synthesis Methods 1, 2 (2010), 112-25.

Shensheng Wang, Scott O. Lilienfeld, and Philippe Rochat. 2015. The uncanny valley: Existence and explanations. Review of General Psychology 19 (2015), 393-407. https://doi.org/10.1037/gpr0000056

Shensheng Wang and Philippe Rochat. 2017. Human perception of animacy in light of the uncanny valley phenomenon. Perception 46, 12 (2017), 1386-1411. https://doi.org/10.1177/0301006617722742

Shensheng Wang, Yuk F. Cheong, Daniel D. Dilks, and Philippe Rochat. 2020. The uncanny valley phenomenon and the temporal dynamics of face animacy perception. Perception 49 (2020), 1069-1089. https://doi.org/10.1177/0301006620952611

Patrick P. Weis and Eva Wiese. 2017. Cognitive conflict as possible origin of the uncanny valley. Proceedings of the Human Factors and Ergonomics Society Annual Meeting 61 (2017), 1599-1603. https://doi.org/10.1177/1541931213601763

Megan T. Wyman, Benjamin D. Charlton, Yann Locatelli, and David Reby. 2011. Variability of female responses to conspecific vs. heterospecific male mating calls in polygynous deer: An open door to hybridization? PLOS One, 6, 8 (2011). https://doi.org/10.1371/journal.pone.0023296

Yuki Yamada, Takahiro Kawabe, and Keiko Ihaya. 2013. Categorization difficulty is associated with negative evaluation in the "uncanny valley" phenomenon. Japanese Psychological Research 55, 1 (2011), 20-32. https://doi.org/10.1111/j.14685884.2012.00538.x

Joachim von Zitzewitz, Patrick M. Boesch, Peter Wolf, and Robert Riener. 2013. Quantifying the human likeness of a humanoid robot. International fournal of Social Robotics 5 (2013), 263-276. https://doi.org/10.1007/s12369-012-0177-4

Angela Tinwell. 2009. Uncanny as usability obstacle. In A. Ant Ozok and Panayiotis Zaphiris (Eds.), Online Communities and Social Computing. Lecture Notes in Computer Science, vol. 5621 (2009). Springer, Berlin. https://doi.org/10.1007/ 978-3-642-02774-1_67

Eduard Zell, Carlos Aliaga, Adrian Jarabo, Katja Zibrek, Diego Gutierrez, Rachel McDonnell, and Mario Botsch. 2015. To stylize or not to stylize? The effect of shape and material stylization on the perception of computer-generated faces. ACM Transactions on Graphics 34, 6 (2015), 184, 1-12. https://doi.org/10.1145/2816795.2818126

Jie Zhang, Shuo Li, Jing-Yu Zhang, Feng Du, Yue Qi, and Xun Liu. 2020. A literature review of the research on the uncanny valley. In Cross-Cultural Design: User Experience of Products, Services, and Intelligent Environments. Pei-Luen Patrick 
Rau (Ed.), Lecture Notes in Computer Science, 12192 (2020). Springer, Cham, Switzerland. https://doi.org/10.1007/9783-030-49788-0_19

Jakub A. Złotowski, Hidenobu Sumioka, Shuichi Nishio, Dylan F. Glas, Christoph Bartneck, and Hiroshi Ishiguro. 2015. Persistence of the uncanny valley: The influence of repeated interactions and a robot's attitude on its perception. Frontiers in Psychology 6 (2015), 883. https://doi.org/10.3389/fpsyg.2015.00883

Received June 2020; revised April 2021; accepted May 2021 